\title{
Constraint Study for a Hand Exoskeleton: Human Hand Kinematics and Dynamics
}

\author{
Fai Chen Chen, Silvia Appendino, Alessandro Battezzato, Alain Favetto, \\ Mehdi Mousavi, and Francesco Pescarmona
}

Center for Space Human Robotics@Polito, Istituto Italiano di Tecnologia, Corso Trento 21, 10129 Torino, Italy

Correspondence should be addressed to Francesco Pescarmona; francesco.pescarmona@iit.it

Received 10 May 2013; Revised 26 July 2013; Accepted 30 July 2013

Academic Editor: Kazuhiko Terashima

Copyright (c) 2013 Fai Chen Chen et al. This is an open access article distributed under the Creative Commons Attribution License, which permits unrestricted use, distribution, and reproduction in any medium, provided the original work is properly cited.

\begin{abstract}
In the last few years, the number of projects studying the human hand from the robotic point of view has increased rapidly, due to the growing interest in academic and industrial applications. Nevertheless, the complexity of the human hand given its large number of degrees of freedom (DoF) within a significantly reduced space requires an exhaustive analysis, before proposing any applications. The aim of this paper is to provide a complete summary of the kinematic and dynamic characteristics of the human hand as a preliminary step towards the development of hand devices such as prosthetic/robotic hands and exoskeletons imitating the human hand shape and functionality. A collection of data and constraints relevant to hand movements is presented, and the direct and inverse kinematics are solved for all the fingers as well as the dynamics; anthropometric data and dynamics equations allow performing simulations to understand the behavior of the finger.
\end{abstract}

\section{Introduction}

The human hand is a complex mechanism; it has a wide range of DoFs, allowing a great variety of movements. In recent years, as robotics has advanced, significant efforts have been devoted to the development of hand devices. The two main related application fields are prosthetic/robotic hands and exoskeletons. On one side, robotic hands are developed with the characteristics complying to those of the human hand, taking advantage of its variety of movements, thereby avoiding the use of a large number of end effectors when performing tasks with different objects (e.g., Eurobot [1], Robonaut [2]). On the other side, exoskeletons are designed to fit onto the human hand, aiming at enhancing performance in the carrying out of daily activities (e.g., improving astronauts' hand performance during extravehicular activity [3]) or supporting the rehabilitation stage of hand injury recovery.

There are currently many different projects underway. Schabowsky et al. [4] introduced a newly developed Hand Exoskeleton Rehabilitation Robot (HEXORR), which was designed to provide a full range of motion for all fingers. NASA and General Motors presented a prototype of the Human Grasp Assist device [5] (K-Glove). Worsnopp et al.
[6] introduced a finger exoskeleton for hand rehabilitation following strokes, to facilitate movement, especially pinch. Another project is being developed by Ho et al. [7]: their exoskeleton hand is EMG driven, again for rehabilitation, but working on all the fingers. All of these projects present a different number of DoFs and different structures, but in general they are developed with the objective of mimicking the main characteristics of the human hand. This implies a complete understanding of these characteristics, involving the anthropometric dimensions of the human hand, its kinematics, and its dynamics.

This paper aims at analyzing all the aforementioned aspects. It is organized as follows: Section 2 presents anthropometric data about the hand, such as dimensions of the hand and phalanges; Section 3 contains the main constraints of finger movements, explaining each type of constraint in the natural movement of the human hand; Section 4 describes the kinematical model of the hand; direct and inverse kinematics are developed step by step. Section 5 presents the dynamics of a single finger; Section 6 shows the implementation of the dynamic equations on a practical example. Finally, conclusions are presented in Section 7. 


\section{Human Hand Data}

The human hand is composed of 5 digits: 4 fingers (index, ring, middle, and little fingers) and the thumb. The thumb is characterized by three articulations and three phalanges. The fingers also comprise three different articulations and four phalanges. Figure 1 shows names and acronyms of each articulation and phalanx. The wrist has two functional DoFs. The TMC joint of the thumb holds two DoFs (flexion/extension and adduction/abduction). A single DoF (flexion/extension) characterizes the MCP and IP joints of the thumb as well as the PIP and DIP joints of the fingers. Whereas the eight bones of the carpus articulate finely with each other producing small deformations, their representation in a single rigid segment is a consistent approximation [8].

The analysis of kinematics and dynamics requires knowledge regarding the dimensions of the fingers and of the palm and their respective range of motion (RoM); those data are reported below. Tables 1 and 2 show the results of Garrett's studies $[9,10]$ for finger lengths and palm dimensions, measurements that were taken from the right hands of 148 men and 211 women. In Table 1, crotch to tip is the distance along the axis of the digit from the midpoint of its tip to the level of the corresponding webbed crotch between two digit; wrist crease to tip is the distance along the axis of the digit from the midpoint of its tip to the wrist crease baseline.

A few researchers have measured the length of each phalanx separately. A study with a variety of candidates is the one performed by Habib and Kamal [11]. The results of their study for each phalanx of index, middle, ring, and little fingers are in Table 3 (I1 means distal phalanx, I 2 middle phalanx, and I3 proximal phalanx of the index finger. The same notation is used for other digits). A similar survey is also present in Jasuja and Singh's study [12]. As shown in Table 3, the average dimensions of the hand are quite similar to the ones presented in Table 2, with a maximum difference of $2.18 \%$. The data presented here is the sample distribution over geographic regions and Air Force Commands, which may be quite representative of possible EVA glove users.

As mentioned above, those data can give us an idea of the mean values of the length of each element that composes the human hand. With proper modifications, this data can also be used to compose a model to simulate its movements: in particular, it must be taken into account that the distance between a joint and a digit webbing is not representative of the equivalent link length. A simulation was performed, and the results are presented in Section 6.

\section{Constraints Overview}

Hand and digit motions are subject to several constraints that limit the range of the natural movements of human fingers. Constraints can be roughly divided into three types: static, intrafinger, and interfinger constraints. Intra- and inter-finger, constraints are often called dynamic constraints that in the fingers of the hand are essentially constraints between joint motions. However, this range of movement is somewhat ambiguous because the range depends on various factors involving human hand biomechanics; therefore they are
TABLE 1: Mean finger lengths and palm dimensions of USAF male $(\mathrm{M}) /$ female (F) flying personnel $[9,10](\mathrm{cm})$.

\begin{tabular}{lccccccccc}
\hline & \multicolumn{3}{c}{$\begin{array}{c}\text { Finger length } \\
\text { (crotch to tip) }\end{array}$} & \multicolumn{4}{c}{$\begin{array}{c}\text { Finger length } \\
\text { (wrist crease to tip) }\end{array}$} \\
\multicolumn{1}{c}{} & Mean & s.d. & $<5 \%$ & $<95 \%$ & Mean & s.d. & $<5 \%$ & $<95 \%$ \\
\hline M & & & & & & & & \\
Thumb & 5.87 & 0.45 & 5.07 & 6.57 & 12.70 & 1.13 & 11.05 & 14.68 \\
Index & 7.53 & 0.46 & 6.83 & 8.19 & 18.52 & 0.88 & 17.33 & 20.06 \\
Middle & 8.57 & 0.51 & 7.82 & 9.74 & 19.52 & 0.92 & 18.10 & 21.04 \\
Ring & 8.0 & 0.47 & 7.44 & 8.93 & 18.72 & 0.91 & 17.52 & 20.28 \\
Little & 6.14 & 0.47 & 5.44 & 6.99 & 16.61 & 0.91 & 15.11 & 18.10 \\
\hline F & & & & & & & & \\
Thumb & 5.37 & 0.44 & 4.68 & 6.12 & 11.05 & 1.00 & 9.51 & 12.83 \\
Index & 6.90 & 0.52 & 6.10 & 7.80 & 16.67 & 0.89 & 15.21 & 18.14 \\
Middle & 7.79 & 0.51 & 7.01 & 8.68 & 17.65 & 0.87 & 16.22 & 19.05 \\
Ring & 7.31 & 0.52 & 6.52 & 8.22 & 16.76 & 8.94 & 15.28 & 18.20 \\
Little & 5.46 & 0.44 & 4.80 & 6.24 & 14.64 & 0.92 & 13.11 & 16.12 \\
\hline
\end{tabular}

TABle 2: Average hand dimensions of USAF male (M)/female (F) flying personnel $[9,10](\mathrm{cm})$.

\begin{tabular}{lc}
\hline Joint & Mean length \\
\hline Hand length & \\
M & 19.72 \\
F & 17.93 \\
Hand breadth & \\
M & 8.96 \\
F & 7.71 \\
Hand circumference & \\
M & 21.59 \\
F & 18.71 \\
Hand thickness & \\
M & 3.29 \\
F & 2.76 \\
Hand depth & \\
M & 6.19 \\
F & 5.17 \\
\hline
\end{tabular}

difficult to be expressed in closed forms (i.e., equations) and how to model such constraints still needs further investigation. The significance of taking finger constraints into consideration is that this causes the DoFs of the human hand to decrease. It is important to underline the fact that different individuals can show significant variations regarding the following constraints.

3.1. Intrafinger Constraints. Intrafinger constraints are constraints between different joints in the same finger. Cobos et al. [14] presented several constraints for fingers and thumb. Equation (1) presents the relation between the joints of a finger, as first proposed by Rijpkema and Girard [15]:

$$
\theta_{\mathrm{DIP}} \approx \frac{2}{3} \theta_{\mathrm{PIP}} \theta_{\mathrm{PIP}} \approx \frac{3}{4} \theta_{\mathrm{MCP}_{f / e}}
$$




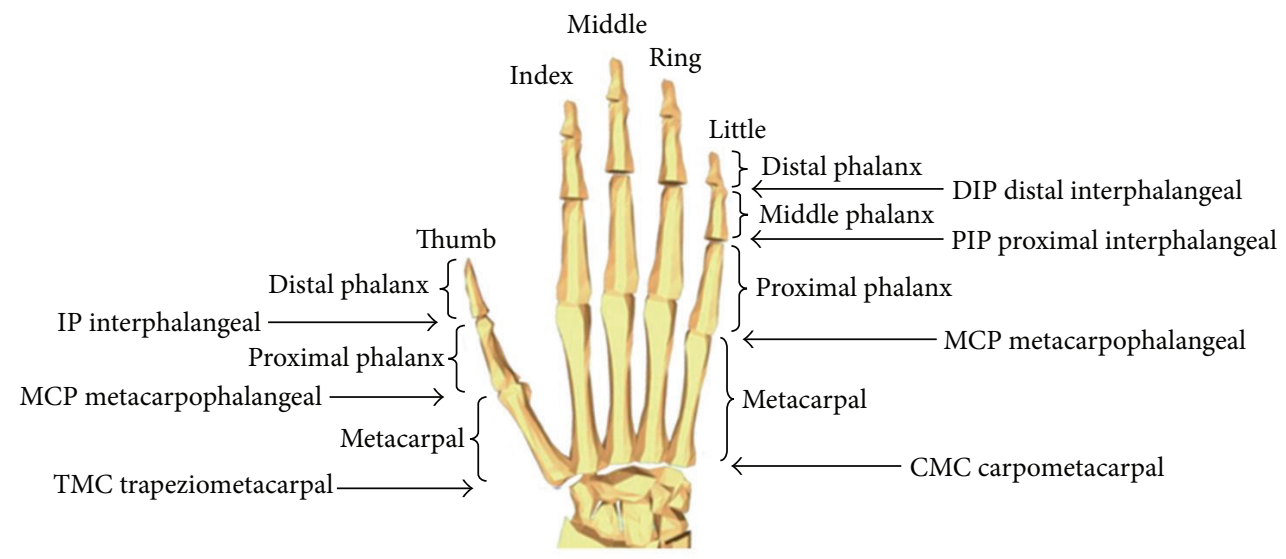

FIGURE 1: Anatomical details of the hand skeleton.

TABLE 3: Mean length of the hand and of the phalanges of index, middle, ring, and little fingers $(\mathrm{cm})$.

\begin{tabular}{lccccccccccccc}
\hline & Hand & I1 & I2 & I3 & M1 & M2 & M3 & R1 & R2 & R3 & L1 & L2 & L3 \\
\hline Male right hand & 19.29 & 2.32 & 2.37 & 2.65 & 2.60 & 2.78 & 2.80 & 2.29 & 2.56 & 2.76 & 1.96 & 1.92 & 2.51 \\
Male left hand & 19.36 & 2.32 & 2.39 & 2.61 & 2.60 & 2.82 & 2.75 & 2.30 & 2.59 & 2.78 & 1.95 & 1.98 & 2.49 \\
Female right hand & 17.60 & 2.23 & 2.24 & 2.45 & 2.44 & 2.55 & 2.56 & 2.12 & 2.34 & 2.52 & 1.79 & 1.74 & 2.26 \\
Female left hand & 17.62 & 2.20 & 2.24 & 2.35 & 2.24 & 2.43 & 2.53 & 2.13 & 2.36 & 2.49 & 1.77 & 1.77 & 2.26 \\
\hline
\end{tabular}

In (2), the constraint relations between the joints when flexing or extending the thumb are

$$
\begin{gathered}
\theta_{\mathrm{IP}} \approx \frac{1}{2} \theta_{\mathrm{MCP}_{f / e},} \\
\theta_{\mathrm{MCP}_{f / e}} \approx \frac{5}{4} \theta_{\mathrm{TMC}_{f / e}} .
\end{gathered}
$$

These constraints are not strict. In fact, there are individuals who are more able than others to control their DIP joint, and anybody can force a behavior slightly out of these equations for any joint. However, in normal conditions those constraints are respected quite faithfully.

It is important to underline that the constraints mentioned above are due to the physiologic nature of the human hand. Additionally, other constraints can be considered, due to ergonomics. In this case, the relations of the constraints are related to a specific task, such as grasping a circular or a prismatic object.

Table 4 shows the typical ergonomic constraints relative to a circular grasping.

Therefore the thumb is defined by 2 DoFs, index finger by 2 DoFs, middle finger by $1 \mathrm{DoF}$, ring finger by $1 \mathrm{DoF}$, and little finger by 3 DoFs. The ring finger is calculated on the basis of the little and middle fingers joints. Therefore, the thumb, the index finger, and the little finger are the most important fingers when defining circular grasps [13].

Table 5 shows the ergonomic intrafinger constraints for a prismatic grasp. As a result, the thumb is defined by $2 \mathrm{DoFs}$, index finger by 2 DoFs, middle finger by $1 \mathrm{DoF}$, ring finger by $1 \mathrm{DoF}$, and little finger by 3 DoFs. Comparing the circular grasping and the prismatic one, the latter presents fewer constraints among fingers.
3.2. Interfinger Constraints. Interfinger constraints correlate two joints belonging to different fingers. For instance, with the hand in the open position (at rest), when one bends the index finger at the MCP joint, the MCP joint of the middle finger bends automatically as well, with respective certain proportionality.

As for intra-finger constraints, different individuals can show important differences. Moreover, also in this case one can forcefully overcome some of these constraints.

On the other hand, there are constraints that cannot be explicitly represented in equations. A few cases are explained below.

Some joints belonging to different fingers seem to be "naturally" interconnected. By that, we mean that the respective angles vary more or less proportionally, that is, unless a voluntary counter force is applied, imposing a different type of motion. However, trying to move a finger in such an unnatural way often results in oddly fatiguing efforts.

For instance, there is a coupled movement when the index finger and little finger are at rest. The flexion of the middle finger is equal to the flexion of the ring finger as described in

$$
\theta_{\mathrm{MCP}_{f / e} \text { Middle }} \approx \theta_{\mathrm{MCP}_{f / e} \text { Ring }} \text {. }
$$

Another coupled movement is produced when flexing the ring finger, thereby causing a slight flexion on the middle finger and on the little finger, that happens to be the same angle rotation as described in

$$
\theta_{\mathrm{MCP}_{f / e} \text { Middle }} \approx \theta_{\mathrm{MCP}_{f / e} \text { Little }} .
$$




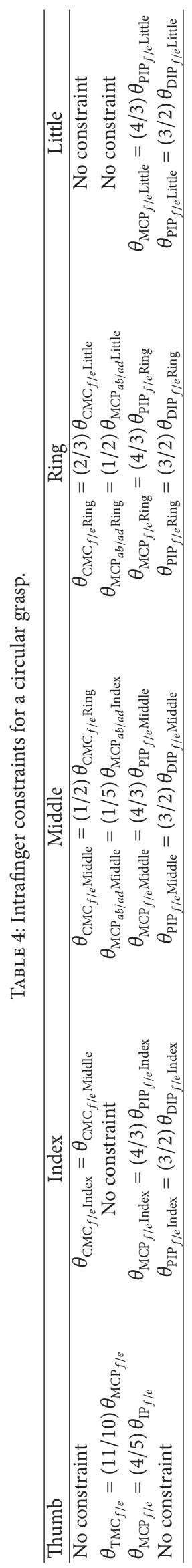




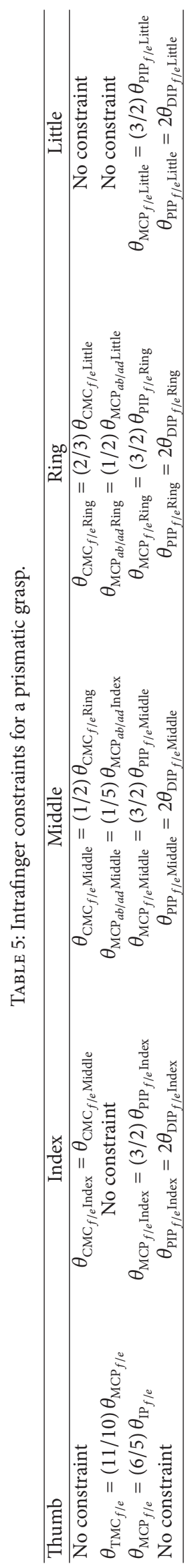


There is also a coupled movement in abduction/adduction, which is generated among ring and little fingers. In most cases, the movement is similar to

$$
\theta_{\mathrm{MCP}_{a b / a d} \text { Ring }} \approx \theta_{\mathrm{MCP}_{a b / a d} \text { Little }} \text {. }
$$

Additionally, some joints can be tied by more intricate relations, divided into two types. The first type occurs when there is a unique motion, like the flexion in the MCP joint of the little finger. Equation (6) represents this type of relation between the fingers

$$
\begin{gathered}
\theta_{\mathrm{MCP}_{f / e} \text { Ring }} \approx \frac{7}{12} \theta_{\mathrm{MCP}_{f / e} \text { Little }} \\
\theta_{\mathrm{MCP}_{f / e} \text { Middle }} \approx \frac{2}{3} \theta_{\mathrm{MCP}_{f / e} \text { Ring }}, \\
\theta_{\mathrm{MCP}_{f / e} \text { Ring }}-\theta_{\mathrm{MCP}_{f / e} \text { Middle }}<60^{\circ}, \\
\theta_{\mathrm{MCP}_{f / e} \text { Little }}-\theta_{\mathrm{MCP}_{f / e} \text { Ring }}<50^{\circ} .
\end{gathered}
$$

These equations indicate that when there is flexion, the ring and middle fingers will also flex in a certain range with respect to the little finger. For instance, when the little finger is flexed, the middle finger will flex $2 / 3$ times the ring finger.

The second relationship is when there is a simple MCP flexion as in the case of the index finger, thereby causing some additional natural movement. Equation (7) represents this type of relation between the index and the middle fingers

$$
\theta_{\mathrm{MCP}_{f / e} \text { Middle }} \approx \frac{1}{5} \theta_{\mathrm{MCP}_{f / e} \text { Index }} .
$$

This relation is only present when there is a single flexion on the index finger MCP joint, so when it occurs, the middle finger MCP joint will flex naturally and passively with this proportionality.

These constraints are important because they express the natural relation between single joints. Thus devices designed to mimic the human hand must comply as precisely as possible with these constraints.

3.3. Static Constraints. The normal range of motion (ROM) of human hand joints corresponds to static constraints on joint angles in the model. These constraints are limits on the values that the $\theta$ parameters can assume. Main static constraints (Table 6) were collected by Cobos et al. [13]. By applying these constraints to the inverse kinematics presented later in Section 4.2, some DoFs can be neglected, and therefore the complexity of the system can be reduced.

\section{Kinematic Model}

The kinematic model proposed here is composed of 19 links corresponding to the human bones and $24 \mathrm{DoFs}$ modeled by rotational joints. Two different kinematic configurations are considered for the fingers, one for the thumb modeled as 3 links and 4 joints and another for the other fingers (index, middle, ring, and little fingers). Each of them is modeled using 4 links and 5 joints, as in Figure 2. Note that the CMC
TABLE 6: Statics constraints [13].

\begin{tabular}{cccc}
\hline Finger & Flexion & Extension & Abd./add. \\
\hline Thumb & & & \\
TMC & $50^{\circ}-90^{\circ}$ & $15^{\circ}$ & $45^{\circ}-60^{\circ}$ \\
MCP & $75^{\circ}-80^{\circ}$ & $0^{\circ}$ & $5^{\circ}$ \\
IP & $75^{\circ}-80^{\circ}$ & $5^{\circ}-10^{\circ}$ & $5^{\circ}$ \\
Index & & & \\
CMC & $5^{\circ}$ & $0^{\circ}$ & $0^{\circ}$ \\
MCP & $90^{\circ}$ & $30^{\circ}-40^{\circ}$ & $60^{\circ}$ \\
PIP & $110^{\circ}$ & $0^{\circ}$ & $0^{\circ}$ \\
DIP & $80^{\circ}-90^{\circ}$ & $5^{\circ}$ & $0^{\circ}$ \\
Middle & & & \\
CMC & $5^{\circ}$ & $0^{\circ}$ & $0^{\circ}$ \\
MCP & $90^{\circ}$ & $30^{\circ}-40^{\circ}$ & $45^{\circ}$ \\
PIP & $110^{\circ}$ & $0^{\circ}$ & $0^{\circ}$ \\
DIP & $80^{\circ}-90^{\circ}$ & $5^{\circ}$ & $0^{\circ}$ \\
Ring & & & \\
CMC & $10^{\circ}$ & $0^{\circ}$ & $0^{\circ}$ \\
MCP & $90^{\circ}$ & $30^{\circ}-40^{\circ}$ & $45^{\circ}$ \\
PIP & $120^{\circ}$ & $0^{\circ}$ & $0^{\circ}$ \\
DIP & $80^{\circ}-90^{\circ}$ & $5^{\circ}$ & $0^{\circ}$ \\
Little & & & $0^{\circ}$ \\
CMC & $15^{\circ}$ & $0^{\circ}$ & $0^{\circ}$ \\
MCP & $90^{\circ}$ & $30^{\circ}-40^{\circ}$ & \\
PIP & $135^{\circ}$ & $0^{\circ}$ & \\
DIP & $90^{\circ}$ & & \\
\hline
\end{tabular}

joint represents the deformation of the palm, for instance, when the hand is grasping a ball, while the MCP abduction/adduction joint is defined before MCP flexion/extension.

4.1. Direct Kinematics. Direct kinematic equations are used to obtain the fingertip position and orientation according to the joint angles. The model equations are calculated by means of modified Denavit-Hartenberg $(\mathrm{MDH})$ parameters, introduced by Craig [16]. The difference from the DenavitHartenberg convention is the fact that, on $\mathrm{MDH}$, the $z$-axis of the reference frame $\{j\}$, called $z_{j}$, is coincident with the axis of joint $j$. In comparison to MD the $z$-axis of the frame $\{j\}$ is coincident with the axis of joint $j+1$. The advantage of using $\mathrm{MDH}$ is that there is no need for further transformation of the references in order to work with the dynamics of the rigid bodies.

4.1.1. Direct Kinematics of the Index, Middle, Ring, and Little Fingers. Each of the fingers contains four bones: metacarpal, proximal, middle, and distal (Figure 1). These bones correspond approximately to the links of the serial kinematic chain (Figure 2). Each articulation presented above for these four fingers corresponds to the joints: CMC, MCP, PIP, and DIP. The MCP joint can be split into $2 \mathrm{DoFs}$, which carry out the adduction/abduction and flexion/extension movements, respectively. All the other joints only allow flexion/extension movements. Having defined a numbering of the fingers, from 

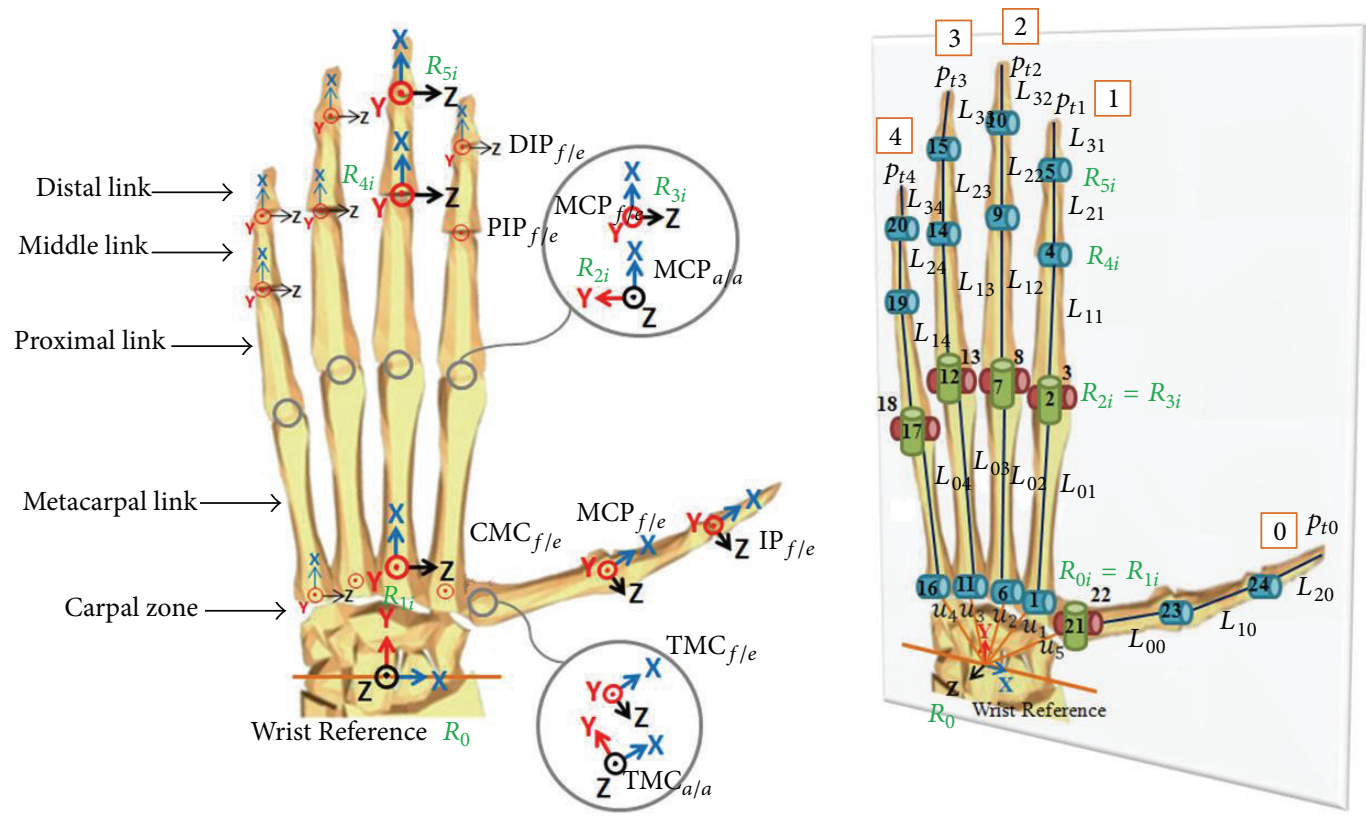

FiguRE 2: Kinematic configuration of the human hand. The thumb is defined by 3 links and 4 degrees of freedom whereas index, middle, ring, and little fingers are defined by 4 links and 5 DoFs.

0 to 4 where finger 0 is the thumb and finger 4 is the little finger, Table 7 shows the MDH parameters for fingers 1 to 4 .

Equation (8) shows the direct kinematics from index $(i=$ 1) to the little finger $(i=4)$

$$
\begin{gathered}
Q_{i}={ }_{0}^{0} T_{i} \cdot{ }_{6}^{0} T_{i}\left(\theta_{j}\right)={ }_{0}^{0} T_{i} \cdot \prod_{j=1}^{5}\left({ }_{j}^{j-1} T_{i}\left(\theta_{j}\right) \cdot{ }_{6}^{5} T_{t_{i}},\right. \\
Q_{i}={ }_{0}^{0} T_{i} \cdot{ }_{1}^{0} T_{i}\left(\theta_{\mathrm{CMC}_{f / e}}\right) \cdot{ }_{2}^{1} T_{i}\left(\theta_{\mathrm{MCP}_{a b / a d}}\right) \cdot{ }_{3}^{2} T_{i}\left(\theta_{\mathrm{MCP}_{f / e}}\right) \\
\\
\cdot{ }_{4}^{3} T_{i}\left(\theta_{\mathrm{PIP}_{f / e}}\right) \cdot{ }_{5}^{4} T_{i}\left(\theta_{\mathrm{DIP}_{f / e}}\right) \cdot{ }_{6}^{5} T_{t_{i}},
\end{gathered}
$$

where

(i) $Q_{i}$ represents a matrix containing the position and orientation of the fingertip of each finger;

(ii) ${ }_{0}^{0} T_{i}$ represents a rototranslation matrix taking into account the fact that the fingers are slightly fanned out and making it possible to pass from the initial base reference frame $\left(R_{0}\right)$ to the alignment of the $i$ th finger first reference frame $\left(R_{0 i}\right)$;

(iii) ${ }_{6}^{0} T_{i}\left(\theta_{j}\right)$ is a matrix containing the geometrical transformation between the $i$ th finger first reference frame and the $i$ th fingertip $\left(\mathrm{ft}_{i}\right)$. The matrix is composed of the concatenation of the transformation matrices of each finger link;

(iv) ${ }_{j}^{(j-1)} T_{i}\left(\theta_{j}\right)$ is a matrix containing the geometrical transformation between the $(j-1)$ th reference frame and the $j$ th reference frame of the $i$ th finger;
TABLE 7: Modified D-H parameters for fingers 1 to 4.

\begin{tabular}{ccccc}
\hline \multicolumn{5}{c}{ Finger $i(i=1, \ldots, 4)$} \\
Joint & $\alpha_{j-1}$ & $a_{j-1}$ & $d_{j}$ & $\theta_{j}$ \\
\hline$j=1$ & $\pi / 2$ & 0 & 0 & $\theta_{\mathrm{CMC}_{f / e}}$ \\
$j=2$ & $-\pi / 2$ & $L_{0 i}$ & 0 & $\theta_{\mathrm{MCP}_{a b / a d}}$ \\
$j=3$ & $\pi / 2$ & 0 & 0 & $\theta_{\mathrm{MCP}_{f / e}}$ \\
$j=4$ & 0 & $L_{1 i}$ & 0 & $\theta_{\mathrm{PIP}_{f / e}}$ \\
$j=5$ & 0 & $L_{2 i}$ & 0 & $\theta_{\mathrm{DIP}_{f / e}}$ \\
\hline
\end{tabular}

(v) ${ }_{6}^{5} T_{t_{i}}$ represents the position $p_{t_{i}}=\left[\begin{array}{lll}l_{t_{i x}} & l_{t_{i y}} & l_{t_{i z}}\end{array}\right]^{T}$ of the fingertip with respect to the distal (5th) reference frame.

$i$ corresponds to index(1), middle(2), ring(3), and little(4) fingers. $j$ corresponds to each finger's joint $\mathrm{CMC}_{f / e}, \mathrm{MCP}_{a b / a d}$, $\mathrm{MCP}_{f / e}, \mathrm{PIP}_{f / e}$, and $\mathrm{DIP}_{f / e} . t_{i}$ stands for the tip of the $i$ th finger.

The coefficients $Q_{i}$, which are the elements of the $s$ th row and $t$ th column of the matrix expressed in (8), relative to the $i$ th finger, are given in Appendix A.

4.1.2. Direct Kinematics of the Thumb. The thumb presents three bones (Figure 1): metacarpal, proximal, and distal. These bones correspond approximately to the length of each link. The respective joints are TMC, MCP, and IP. The TMC joint presents 2 DoFs, allowing adduction/abduction 
TABLE 8: Modified D-H parameters of the thumb.

\begin{tabular}{ccccc}
\hline Joint & $\alpha_{j-1}$ & $a_{j-1}$ & $d_{j}$ & $\theta_{j}$ \\
\hline$j=1$ & 0 & 0 & 0 & $\theta_{\mathrm{TMC}_{a b / a d}}$ \\
$j=2$ & $\pi / 2$ & 0 & 0 & $\theta_{\mathrm{TMC}_{f / e}}$ \\
$j=3$ & 0 & $L_{00}$ & 0 & $\theta_{\mathrm{MCP}_{f / e}}$ \\
$j=4$ & 0 & $L_{10}$ & 0 & $\theta_{\mathrm{IP}_{f / e}}$ \\
\hline
\end{tabular}

and flexion/extension. Table 8 shows the MDH parameters. Equation (9), with the same notation scheme as (8), shows the direct kinematics for the thumb

$$
\begin{gathered}
Q_{0}={ }_{0}^{0} T_{0} \cdot{ }_{5}^{0} T_{0}\left(\theta_{k}\right), \\
Q_{0}={ }_{0}^{0} T_{0} \cdot{ }_{1}^{0} T_{0}\left(\theta_{\mathrm{TMC}_{a b / a d}}\right) \cdot{ }_{2}^{1} T_{0}\left(\theta_{\mathrm{TMC}_{f / e}}\right) \\
\cdot{ }_{3}^{2} T_{0}\left(\theta_{\mathrm{MCP}_{f / e}}\right) \cdot{ }_{4}^{3} T_{0}\left(\theta_{\mathrm{IP}_{f / e}}\right) \cdot{ }_{5}^{4} T_{t_{0}},
\end{gathered}
$$

where $k$ corresponds to the thumb joint $\mathrm{TMC}_{a b / a d}, \mathrm{TMC}_{f / e}$, $\mathrm{MCP}_{f / e}$, and $\mathrm{IP}_{f / e}$. The position of the fingertip is $p_{t_{0}}=$ $\left[\begin{array}{lll}l_{t_{0 x}} & l_{t_{0 y}} & l_{t_{0 z}}\end{array}\right]^{T}$. The coefficients $Q_{0_{s t}}$ of the matrix expressed in (9) are given in Appendix A.

4.2. Inverse Kinematics. Inverse kinematics is used to obtain the joint angle values according to the fingertip position and orientation. The inverse kinematics will be solved separately for the thumb and for the other fingers. The model of the human hand is a redundant case; therefore several solutions to the inverse kinematic problem exist. In order to find a unique solution, it is necessary to take into account the constraints presented in Section 3.

4.2.1. Inverse Kinematics of a Finger (Index $(i=1)$ to Little Finger $(i=4))$. The angles $\theta_{i_{-} \mathrm{CMC}_{f / e}}, \theta_{i_{-} \mathrm{MCP}_{a b / a d}}, \theta_{i \mathrm{MCP}_{f / e}}$, and $\theta_{i_{i} \mathrm{PIP}_{f / e}}, \theta_{i_{-} \mathrm{DIP}_{f / e}}$ are obtained from (8), where the matrix $Q_{i}$, that is, the left member of the equation, is known. Hence, algebraically we solve the inverse kinematics for the $\mathrm{CMC}_{f / e}$, $\mathrm{MCP}_{a b / a d}$, and $\mathrm{DIP}_{f / e}$ joints. The procedure here shown solves the kinematics of the index finger $(i=1)$; however, it is valid for every other finger except the thumb $(i=2,3,4)$. For sake of brevity in the following, the $i$ index is omitted.

The duplication of solutions, when solving an arctangent, for example, is eliminated thanks to the constraints of Section 3.3, because the ranges of all physiological angles are smaller than $180^{\circ}$ and most of them are smaller than $90^{\circ}$. This fact is implicitly taken into account in the following.

$$
\begin{gathered}
\theta_{\mathrm{CMC}_{f / e}}=\operatorname{atan}\left(\frac{Q_{33}}{Q_{13}}\right), \\
\theta_{\mathrm{MCP}_{a b / a d}}=\operatorname{atan}\left[\frac{Q_{13}}{-Q_{23} \cos \left(\theta_{\mathrm{CMC}_{f / e}}\right)}\right], \\
\theta_{\mathrm{DIP}_{f / e}}=\operatorname{atan}\left(\frac{\epsilon_{1}}{\epsilon_{2}}\right),
\end{gathered}
$$

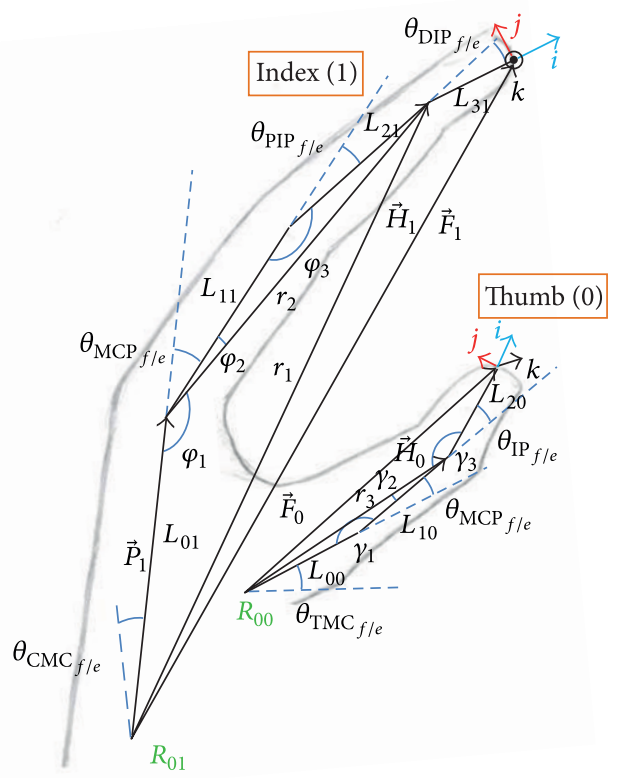

FIGURE 3: Inverse kinematics for the index finger and thumb.

where $\epsilon_{1}$ and $\epsilon_{2}$ are expressed as

$$
\begin{gathered}
\epsilon_{1}=\frac{(-1) \cdot\left(m Q_{22}+n Q_{21}\right)}{\left(m^{2}-n^{2}\right)}, \\
\epsilon_{2}=\frac{\mathrm{Q}_{21}}{m}+\frac{n}{m} \cdot \frac{(-1) \cdot\left(m Q_{22}+n Q_{21}\right)}{\left(m^{2}-n^{2}\right)}, \\
m=\sin \left(\theta_{\mathrm{MCP}_{a b / a d}}\right) \cos \left(\theta_{\mathrm{MCP}_{f / e}}\right) \cos \left(\theta_{\mathrm{PIP}_{f / e}}\right) \\
-\sin \left(\theta_{\mathrm{MCP}_{a b / a d}}\right) \sin \left(\theta_{\mathrm{MCP}_{f / e}}\right) \sin \left(\theta_{\mathrm{PIP}_{f / e}}\right), \\
n=\sin \left(\theta_{\mathrm{MCP}_{a b / a d}}\right) \cos \left(\theta_{\mathrm{MCP}_{f / e}}\right) \sin \left(\theta_{\mathrm{PIP}_{f / e}}\right) \\
-\sin \left(\theta_{\mathrm{MCP}_{a b / a d}}\right) \sin \left(\theta_{\mathrm{MCP}_{f / e}}\right) \cos \left(\theta_{\mathrm{PIP}_{f / e}}\right) .
\end{gathered}
$$

The $\mathrm{MCP}_{f / e}, \mathrm{PIP}_{f / e}$ joints are solved through a geometric method; see Figure 3.

Starting from the vector $\vec{F}_{1}$ which contains the position of the fingertip, it is possible to obtain $\vec{H}_{1}$ with the following expression:

$$
\vec{H}_{1}=\vec{F}_{1}-\left[L_{31} * \hat{i}\right]
$$

Then, the vector $\vec{P}_{1}$ is expressed as

$$
\vec{P}_{1}=\left[\begin{array}{lll}
P_{1 x} & P_{1 y} & P_{1 z}
\end{array}\right]^{T},
$$

where

$$
\begin{aligned}
& P_{1 x}=L_{01} \cos \left(\theta_{\mathrm{CMC}}\right), \\
& P_{1 y}=L_{01} \sin \left(\theta_{\mathrm{CMC}}\right), \\
& P_{1 z}=0 .
\end{aligned}
$$


Knowing $\vec{H}_{1}$ and $\vec{P}_{1}$ from (12) and (13), the vector $\vec{u}_{1}$ is expressed as

$$
\vec{u}_{1}=\vec{H}_{1}-\vec{P}_{1} .
$$

Angles $\varphi_{1}$ and $\varphi_{2}$ are expressed as

$$
\begin{aligned}
& \varphi_{1}=\operatorname{acos}\left(\frac{r_{2}^{2}+L_{01}^{2}-r_{1}^{2}}{2 r_{2} l_{01}}\right), \\
& \varphi_{2}=\operatorname{acos}\left(\frac{r_{2}^{2}+L_{11}^{2}-L_{21}^{2}}{2 r_{2} L_{11}}\right)
\end{aligned}
$$

with variables $r_{1}$ and $r_{2}$ equal to

$$
\begin{aligned}
& r_{1}=\left\|\vec{H}_{1}\right\|, \\
& r_{2}=\left\|\vec{u}_{1}\right\| .
\end{aligned}
$$

So $\theta_{\mathrm{MCP}_{f / e}}$ is obtained as

$$
\theta_{\mathrm{MCP}_{f / e}}=\pi-\varphi_{1}-\varphi_{2}
$$

And $\theta_{\operatorname{PIP}_{f / e}}$ is obtained as

$$
\theta_{\mathrm{PIP}_{f / e}}=\pi-\varphi_{3}
$$

where

$$
\varphi_{3}=\operatorname{acos}\left(\frac{L_{21}^{2}+L_{11}^{2}-r_{2}^{2}}{2 L_{21} L_{11}}\right) .
$$

4.2.2. Inverse Kinematics of the Thumb. A similar procedure can be applied to the thumb, in which $Q_{0}$, that is, the left side of (9), is known; then the joint angle $\theta_{\mathrm{TMC}_{a b / a d}}$ is obtained algebraically as follows:

$$
\theta_{\mathrm{TMC}_{a b / a d}}=\operatorname{atan}\left(\frac{Q_{13}}{-Q_{23}}\right),
$$

where the $Q_{s t}$ term in (21) is the element of the $s$ th row and $t$ th column of the $Q_{0}$ matrix. Then, using the geometrical method (Figure 3), the joint angles $\theta_{\mathrm{MCP}_{f / e}}$ and $\theta_{\mathrm{IP}_{f / e}}$ can be obtained:

$$
\begin{aligned}
\theta_{\mathrm{MCP}_{f / e}} & =\pi-\gamma_{1}, \\
\theta_{\mathrm{IP}_{f / e}} & =\pi-\gamma_{2}-\gamma_{3},
\end{aligned}
$$

where

$$
\begin{gathered}
\gamma_{1}=\operatorname{acos}\left(\frac{L_{10}^{2}+L_{00}^{2}-r_{3}^{2}}{2 L_{10} L_{00}}\right), \\
\gamma_{2}=\operatorname{acos}\left(\frac{L_{20}^{2}+s_{3}^{2}-r_{4}^{2}}{2 L_{20} r_{3}}\right), \\
\gamma_{3}=\operatorname{acos}\left(\frac{r_{3}^{2}+L_{10}^{2}-L_{00}^{2}}{2 r_{s} L_{10}}\right), \\
r_{3}=\left\|\vec{H}_{0}\right\|, \\
r_{4}=\left\|\vec{F}_{0}\right\|, \\
\vec{H}_{0}=\vec{F}_{0}-\left[L_{20} * \hat{i}\right] .
\end{gathered}
$$

The joint $\theta_{\mathrm{TMC}_{f / e}}$ is obtained algebraically as follows:

$$
\theta_{\mathrm{TMC}_{f / e}}=\operatorname{atan}\left(\frac{\epsilon_{4}}{\epsilon_{3}}\right),
$$

where

$$
\begin{gathered}
\epsilon_{3}=\left(Q_{32}+Q_{31}\right) \cos \mu, \\
\epsilon_{4}=\frac{A_{31}-\left(Q_{31}+Q_{32}\right) \cos \mu \cdot \sin \mu}{\cos \mu}, \\
\mu=\theta_{\mathrm{MCP}}+\theta_{\mathrm{IP}} .
\end{gathered}
$$

\section{Dynamics of a Single Finger}

This section provides the dynamics equation system of a generic single finger, neglecting the MCP abduction/adduction motion. The $i$ th index is again omitted. Based on the convention of Figure 4, the dynamic model is determined using Euler-Lagrange equations. It is important to highlight the fact that on the model the metacarpus is fixed, while only the finger phalanges are moving parts. Thus, $R_{2}$ is the base reference system, and all the equations are written with respect to $R_{2}$.

The following equations are applicable to any $3 \mathrm{R}$ planar robot, after making the necessary adaptations to the variables.

The equations require the estimation of the kinetic energy and potential energy, as shown in the following.

In order to simplify the expressed vectors and further developments, the following notation is used:

$$
\begin{aligned}
& \theta_{3}=\theta_{\mathrm{MCP}_{f / e}}, \\
& \theta_{4}=\theta_{\mathrm{PIP}_{f / e}}, \\
& \theta_{5}=\theta_{\mathrm{DIP}_{f / e}},
\end{aligned}
$$

The kinetic energy is calculated starting from the position vectors of the center of mass of each phalanx with respect to the base reference frame $R_{2}$; in general, the position of the center of mass of the $j$ th phalanx with respect to the $j$ reference frame is

$$
\vec{G}_{g}=\left[\begin{array}{c}
b_{g x} \\
b_{g y} \\
0
\end{array}\right] ; \quad g=1,2,3 .
$$

The mass of the $j$ th phalanx is equal to $m_{g}$, and the respective moment of inertia with respect to the axis $z$ is equal to $I_{g}$.

Thus, each position vector with respect to the base reference frame $R_{2}$ is presented below, where $c \theta_{j}$ and $s \theta_{j}$ stand for cosine and sine of $\theta_{j}$, respectively. Consider

$$
\vec{G}_{1}=\left[\begin{array}{c}
b_{1 x} c \theta_{3}-b_{1 y} s \theta_{3} \\
b_{1 x} s \theta_{3}+b_{1 y} c \theta_{3} \\
0
\end{array}\right]
$$

$$
\vec{G}_{2}=\left[\begin{array}{c}
L_{1} c \theta_{3} \\
L_{1} s \theta_{3} \\
0
\end{array}\right]+\left[\begin{array}{c}
b_{2 x} c\left(\theta_{3}+\theta_{4}\right)-b_{2 y} s\left(\theta_{3}+\theta_{4}\right) \\
b_{2 x} s\left(\theta_{3}+\theta_{4}\right)+b_{2 y} c\left(\theta_{3}+\theta_{4}\right) \\
0
\end{array}\right] \text {, }
$$



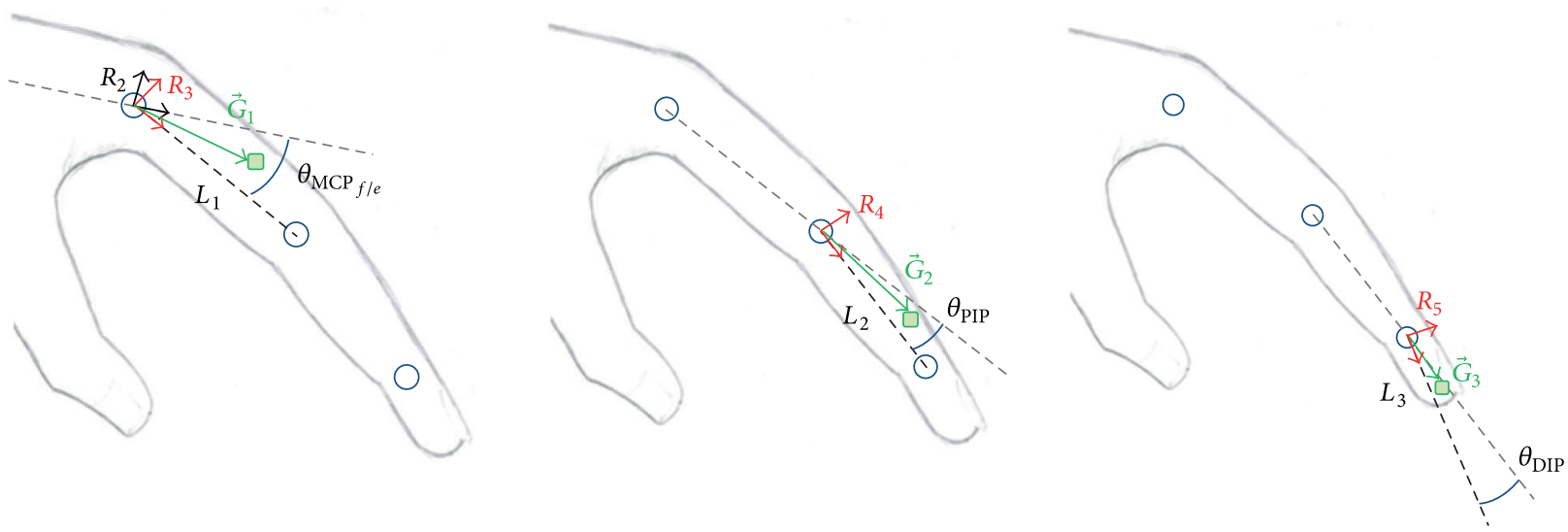

Figure 4: Dynamic model of index(1).

$$
\begin{aligned}
\vec{G}_{3}= & {\left[\begin{array}{c}
L_{1} c \theta_{3} \\
L_{1} s \theta_{3} \\
0
\end{array}\right]+\left[\begin{array}{c}
L_{2} c\left(\theta_{3}+\theta_{4}\right) \\
L_{2} s\left(\theta_{3}+\theta_{4}\right) \\
0
\end{array}\right] } \\
+ & {\left[\begin{array}{c}
b_{3 x} c\left(\theta_{3}+\theta_{4}+\theta_{5}\right)-b_{3 y} s\left(\theta_{3}+\theta_{4}+\theta_{5}\right) \\
b_{3 x} s\left(\theta_{3}+\theta_{4}+\theta_{5}\right)+b_{3 y} c\left(\theta_{3}+\theta_{4}+\theta_{5}\right) \\
0
\end{array}\right] . }
\end{aligned}
$$

The velocities can be obtained by differentiating the position vectors with respect to time, taking into account the following notation of (29) and representing time derivatives through dot notation:

$$
\begin{gathered}
\theta_{3}+\theta_{4}=\theta_{34}, \\
\dot{\theta}_{3}+\dot{\theta}_{4}=\dot{\theta}_{34}, \\
\theta_{3}+\theta_{4}+\theta_{5}=\theta_{345}, \\
\dot{\theta}_{3}+\dot{\theta}_{4}+\dot{\theta}_{5}=\dot{\theta}_{345} .
\end{gathered}
$$

The velocities of each center of mass are obtained:

$$
\begin{gathered}
v_{G_{1}}=\left[\begin{array}{c}
-b_{1 x} \dot{\theta}_{3} s \theta_{3}-b_{1 y} \dot{\theta}_{3} c \theta_{3} \\
b_{1 x} \dot{\theta}_{3} c \theta_{3}-b_{1 y} \dot{\theta}_{3} s \theta_{3} \\
0
\end{array}\right], \\
v_{G_{2}}=\left[\begin{array}{c}
-L_{1} \dot{\theta}_{3} s \theta_{3}-b_{2 x} \dot{\theta}_{34} s \theta_{34}-b_{2 y} \dot{\theta}_{34} c \theta_{34} \\
L_{1} \dot{\theta}_{3} c \theta_{3}+b_{2 x} \dot{\theta}_{34} c \theta_{34}-b_{2 y} \dot{\theta}_{34} s \theta_{34} \\
0
\end{array}\right], \\
v_{G_{3}}=\left[\begin{array}{c}
-L_{1} \dot{\theta}_{3} s \theta_{3}-L_{2} \dot{\theta}_{34} s \theta_{34}-b_{3 x} \dot{\theta}_{345} s \theta_{345}-b_{3 y} \dot{\theta}_{345} c \theta_{345} \\
L_{1} \dot{\theta}_{3} c \theta_{3}+L_{2} \dot{\theta}_{34} c \theta_{34}+b_{3 x} \dot{\theta}_{345} c \theta_{345}-b_{3 y} \dot{\theta}_{345} s \theta_{345} \\
0
\end{array}\right] .
\end{gathered}
$$

The kinetic energy is expressed as

$$
\begin{aligned}
T= & \frac{1}{2} m_{1}\left(v_{G_{1}}\right)^{2}+\frac{1}{2} m_{2}\left(v_{G_{2}}\right)^{2}+\frac{1}{2} m_{3}\left(v_{G_{3}}\right)^{2} \\
& +\frac{1}{2} I_{1}\left(\dot{\theta}_{3}\right)^{2}+\frac{1}{2} I_{2}\left(\dot{\theta}_{34}\right)^{2}+\frac{1}{2} I_{3}\left(\dot{\theta}_{345}\right)^{2} .
\end{aligned}
$$

There are two forms of potential energy considered in this study: the gravitational potential energy and the elastic potential energy. Regarding the elastic potential energy, the value of the stiffness is considered as an average value (constant value $k_{g}$ ) in this study, as a close approximation of the nonlinear and anisotropic finger stiffness (i.e., it varies with the direction). $k_{1}, k_{2}$, and $k_{3}$ are the stiffness values for the MCP, DIP, and PIP joints, respectively [17].

The potential energy for the finger is expressed as

$$
\begin{aligned}
U= & m_{1} g\left(b_{1 x} s \theta_{3}+b_{1 y} c \theta_{3}\right) \\
& +m_{2} g\left(L_{1} s \theta_{3}+b_{2 x} s \theta_{34}+b_{2 y} c \theta_{34}\right) \\
& +m_{3} g\left(L_{1} s \theta_{3}+L_{2} s \theta_{34}+b_{3 x} s \theta_{345}+b_{3 y} c \theta_{345}\right) \\
& +\frac{1}{2} k_{1}\left(\theta_{3}\right)^{2}+\frac{1}{2} k_{2}\left(\theta_{34}-\theta_{3}\right)^{2}+\frac{1}{2} k_{3}\left(\theta_{345}-\theta_{34}\right)^{2} .
\end{aligned}
$$

Moreover, introducing a function of the generalized velocities, usually referred to as the Rayleigh dissipation function $F$, for the damping forces, this function is expressed as

$$
F=\frac{1}{2} c_{1}\left(\dot{\theta}_{3}\right)^{2}+\frac{1}{2} c_{2}\left(\dot{\theta}_{34}-\dot{\theta}_{3}\right)^{2}+\frac{1}{2} c_{3}\left(\dot{\theta}_{345}-\dot{\theta}_{34}\right)^{2}
$$

where the damping constant $\left(c_{g}\right)$ stands for the nonconservative contribution caused by the muscles, actuating the finger. Nonconservative forces contributed less than $15 \%$ to the total force response to static displacement. Muscle viscosity is dissipative and, hence, non-conservative, resulting in a force field with nonzero curl [17]. To be more precise, values $c_{1}$, $c_{2}$, and $c_{3}$ are the damping values for the MCP, DIP, and PIP joints, respectively. 
The Euler-Lagrange equations thus become, considering the three generalized coordinates $\theta_{3}, \theta_{34}$, and $\theta_{345}$,

$$
\begin{aligned}
& \frac{d}{d t}\left(\frac{\partial(T-U)}{\partial \dot{\theta}_{3}}\right)-\frac{\partial(T-U)}{\partial \theta_{3}}+\frac{\partial F}{\partial \dot{\theta}_{3}}=\tau_{3}, \\
& \frac{d}{d t}\left(\frac{\partial(T-U)}{\partial \dot{\theta}_{34}}\right)-\frac{\partial(T-U)}{\partial \theta_{34}}+\frac{\partial F}{\partial \dot{\theta}_{34}}=\tau_{4}, \\
& \frac{d}{d t}\left(\frac{\partial(T-U)}{\partial \dot{\theta}_{345}}\right)-\frac{\partial(T-U)}{\partial \theta_{345}}+\frac{\partial F}{\partial \dot{\theta}_{345}}=\tau_{5}
\end{aligned}
$$

in which the $\tau_{j}(j=3,4,5)$ terms contain the forces applied through the muscles in order to actuate the phalanges and the contact forces, shown in Figure 5.

According to the virtual work principle, the equation to calculate the generalized force can be expressed as

$$
\tau_{j}=\frac{\left(\sum_{j=3}^{5} \delta W_{j}\right)}{\delta \theta_{j}} ; j=3,4,5,
$$

where $\delta W_{j}$ is the virtual work done by the force applied to the system. In the current case, it is

$$
\begin{aligned}
& \tau_{3}=\left(F_{3 y} e_{3 x}-F_{3 x} e_{3 y}\right)+\left[\begin{array}{c}
-L_{1} s \theta_{3} \\
L_{1} c \theta_{3} \\
0
\end{array}\right] \\
& \cdot\left[\begin{array}{c}
F_{4 x} c \theta_{34}-F_{4 y} \mathrm{~s} \theta_{34} \\
F_{4 x} \mathrm{~s} \theta_{34}+F_{4 y} \mathrm{c} \theta_{34} \\
0
\end{array}\right]+\left[\begin{array}{c}
-L_{1} s \theta_{3} \\
L_{1} c \theta_{3} \\
0
\end{array}\right] \\
& \cdot\left[\begin{array}{c}
F_{5 x} \mathrm{c} \theta_{345}-F_{5 y} \mathrm{~s} \theta_{345} \\
F_{5 x} \mathrm{~s} \theta_{345}+F_{5 y} \mathrm{c} \theta_{345} \\
0
\end{array}\right]+C_{m 1}-C_{m 2} \text {, } \\
& \tau_{4}=\left(F_{4 y} e_{4 x}-F_{4 x} e_{4 y}\right)+\left[\begin{array}{c}
-L_{2} s \theta_{34} \\
L_{2} c \theta_{34} \\
0
\end{array}\right] \\
& \cdot\left[\begin{array}{c}
F_{5 x} \mathrm{c} \theta_{345}-F_{5 y} \mathrm{~s} \theta_{345} \\
F_{5 x} \mathrm{~s} \theta_{345}+F_{5 y} \mathrm{c} \theta_{345} \\
0
\end{array}\right]+C_{m 2}-C_{m 3}, \\
& \tau_{5}=\left(F_{5 y} e_{5 x}-F_{5 x} e_{5 y}\right)+C_{m 3},
\end{aligned}
$$

where the term $C_{m g}$ refers to the torque produced by the muscles on the $j$ th joint, and $F_{j}=\left[\begin{array}{lll}F_{j x} & F_{j y} & 0\end{array}\right]^{T}$ is the contact force applied to the $j$ th phalanx at the point defined by the position vector $e_{j}=\left[\begin{array}{lll}e_{j x} & e_{i y} & 0\end{array}\right]^{T}$.

Calculating each element of the Euler-Lagrange equations, the dynamical system (33) becomes

$$
\begin{gathered}
A_{1} \ddot{\theta}_{3}+A_{2} \ddot{\theta}_{34}+A_{3} \ddot{\theta}_{345}=A_{4}, \\
B_{1} \ddot{\theta}_{3}+B_{2} \ddot{\theta}_{34}+B_{3} \ddot{\theta}_{345}=B_{4}, \\
C_{1} \ddot{\theta}_{3}+C_{2} \ddot{\theta}_{34}+C_{3} \ddot{\theta}_{345}=C_{4} .
\end{gathered}
$$

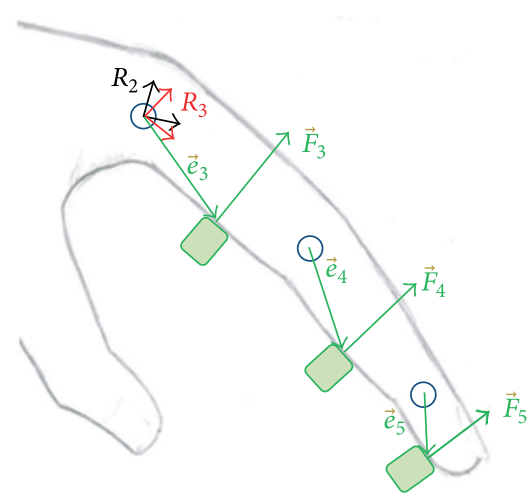

Figure 5: Contact forces.

The terms $A_{1}, A_{2}$, and $A_{3}$ contain the coefficients of the accelerations and $A_{4}$ the remaining terms; the same goes for the other Euler-Lagrange equations.

Equation (37) allows the direct dynamics of the finger to be solved, where, given the torques exerted by the muscles on each phalange, the movement of the finger can be calculated. If, on the other side, an inverse dynamics problem is set, it is simple to rearrange the equation system (33) to obtain the trend of the unknown muscle torques from the phalanges motion laws.

An expansion of the coefficients of equation (37) can be found in Appendix B, equation (B.1).

\section{No-Load Joint Velocities}

A test campaign was carried out, in order to evaluate the maximum angular velocities of the finger joints. Ten male and ten female subjects were asked to perform the following operation as fast as possible during 10 seconds (i.e., before any fatigue phenomenon arises to deteriorate the subject performance): starting from the completely extended hand, they have to flex the fingers to a fist and then to extend them again. The maximum flexion angles for the index finger, corresponding to the fist configuration on each cycle, have been statically measured on the subjects as $85 \mathrm{deg}$ for the MCP joint, 105 deg for the PIP joint, and 70 deg for the DIP one. In the following, those angles will be considered negative in accordance with the notations of Section 4.1. Ten male and ten female subjects were involved in the investigation: the statistical output of the test is reported in Table 9.

There are no significant differences between the male and the female subjects. The results obtained by our test campaign show velocities in accordance with previous tests, for instance, in [18].

The trend of the phalange angles was supposed to follow a sinusoidal law, in the form $\theta_{j}=\left(D_{j} / 2\right)\left(\cos \left(\pi t / t_{1}\right)-1\right)$, where $j=3,4,5$. The term $D_{j}$ is the range of the movement on the $j$ th joint, while $t_{1}=10 \mathrm{~s} /$ num $_{\text {cycles }}$ is the period of each cycle. The time differentiation of this law permits obtaining the trend of the velocities, as well as the maximum angular velocity of each joint, equal to $\dot{\theta}_{j_{-} \max }=\left|-\pi D_{j} / 2 t_{1}\right|$.

Here, such experimental motion law has been implemented in the dynamic modeling of the finger. The simulation 
TABLE 9: Joint velocity tests.

\begin{tabular}{|c|c|c|c|c|c|c|c|c|c|c|c|c|c|c|c|}
\hline Males & $\mathrm{P} A B$ & $\mathrm{AF}$ & MP & $\mathrm{AL}$ & $\mathrm{NC}$ & MS & $\mathrm{AL}$ & $\mathrm{DM}$ & $\mathrm{RC}$ & Mean & st.dev. & $\begin{array}{l}\text { Average freq. } \\
(\mathrm{Hz})\end{array}$ & $\begin{array}{l}\text { Omega max. } \\
\text { MCP (rad/s) }\end{array}$ & $\begin{array}{l}\text { Omega max. } \\
\text { PIP (rad/s) }\end{array}$ & $\begin{array}{l}\text { Omega max. } \\
\text { DIP ( } \mathrm{rad} / \mathrm{s})\end{array}$ \\
\hline Cycles in 10 s 27 & $7 \quad 27$ & 31 & 25 & 20 & 29 & 23 & 27 & 21 & 31 & 26.1 & 3.843 & 2.61 & 12.164 & 15.026 & 10.018 \\
\hline Females & A TT & NG & $\mathrm{FC}$ & EA & GM & $\mathrm{VC}$ & SP & MQ & $\mathrm{DH}$ & Mean & st.dev. & $\begin{array}{c}\text { Average freq. } \\
(\mathrm{Hz})\end{array}$ & $\begin{array}{l}\text { Omega max. } \\
\text { MCP (rad/s) }\end{array}$ & $\begin{array}{l}\text { Omega max. } \\
\text { PIP (rad/s) }\end{array}$ & $\begin{array}{c}\text { Omega max. } \\
\text { DIP }(\mathrm{rad} / \mathrm{s})\end{array}$ \\
\hline Cycles in 10 s 27 & $7 \quad 24$ & 17 & 34 & 29 & 27 & 30 & 24 & 21 & 27 & 26 & 4.784 & 2.6 & 12.118 & 14.969 & 9.979 \\
\hline
\end{tabular}

deals with an inverse dynamics case study: given the motion law of the system (i.e., the kinematic angles of the phalanges and their time derivatives), the torques exerted by the muscles on each phalanx are calculated. In order to evaluate correctly such torques in absence of load, it is necessary to insert also the viscoelastic term that can be preponderant with respect to the dynamical term [19]. The values of the stiffness and the damping coefficients for the MCP joint are obtained through an extrapolation of the values of MCP stiffness and damping, reported in a series of tests in [20], for the noload case, where the applied external force is null. Then, given the fact that the tests in [20] compute translational stiffness and damping coefficients, they are transformed into rotational ones, to be coherent with the dynamic modeling. The resulting coefficients are shown in Table 11, reported in the appendix, together with the anthropometric data and numerical constants imposed in the model to simulate the behavior of a human index finger.

The trends of the muscle torques $C_{m 1}, C_{m 2}$, and $C_{m 3}$ are reported in Figure 6. First of all, these values can be compared with the maximum torque capability of each phalange: Hasser [18] reports these maximum values as $C_{m_{\max }}=$ $\left[\begin{array}{lll}4630 & 2280 & 775\end{array}\right]^{T}$. The current test, without external load, correctly produces a set of torques that are quite lower than these limits. Moreover, the results shown in [19] state that the average total torque for a complete flexion-extension movement of the MCP joint is $100.8 \mathrm{Nmm}$ for the female subjects and $194.9 \mathrm{Nmm}$ for the male ones: these values are quite near to the ones produced here, where the joint velocity is higher. The same paper states that the contribute of the viscoelastic terms is preponderant with respect to the dynamical one: the same is true for the current analysis, where the coefficients $f_{k j}=\left|C_{k j}\right| /\left|C_{m j}\right|, f_{c j}=\left|C_{c j}\right| /\left|C_{m j}\right|$ and $f_{d j}=\left|C_{d j}\right| /\left|C_{m j}\right|$, that are, respectively, the torque portion due to the stiffness term, the damping term, and the dynamic term for the $j$ th phalange, are reported in Table 10. However, if [19] shows that the stiffness term is about the double of the damping one, in the current analysis the situation is reversed: it is presumably due to the higher velocity investigated here.

In conclusion, the results of the current simulation are in good accordance with the literature data. More precise results could be obtained as a consequence of a more accurate estimation of the dynamical parameters inserted into the model, in particular the stiffness and the damping coefficients. For example, due to lack of data, in the current simulation these parameters have been set as equal for the MCP, PIP, and DIP joints: in reality, the PIP and DIP joints have different

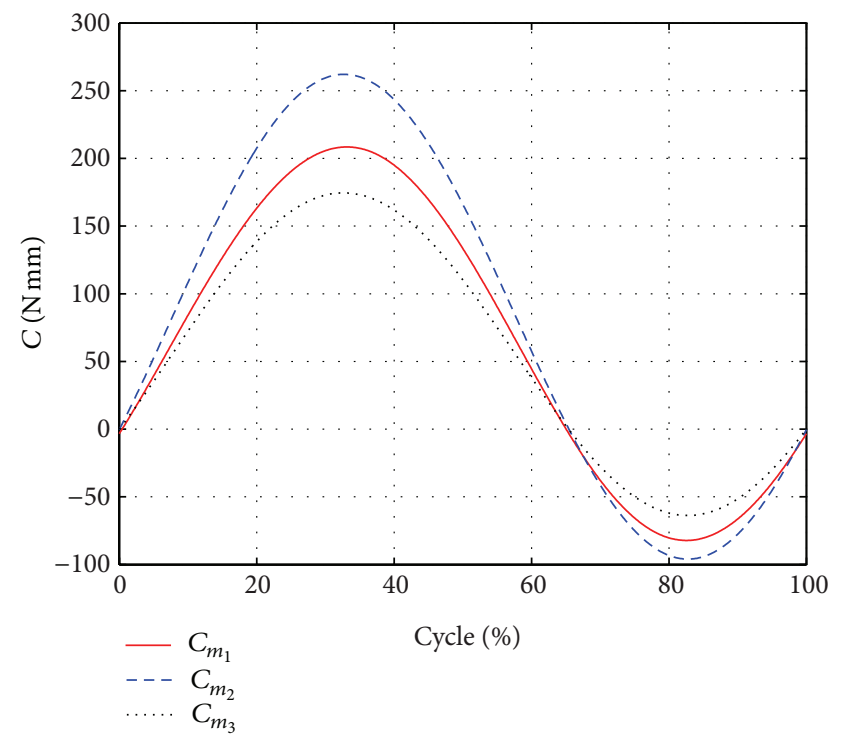

FIGURE 6: Trend of the muscle torques.

TABLE 10: Percentages of stiffness, damping, and inertial torques with respect to the total torque.

\begin{tabular}{lccc}
\hline & MCP & PIP & DIP \\
\hline$f_{k j}$ & $38.05 \%$ & $38.48 \%$ & $38.58 \%$ \\
$f_{c j}$ & $57.58 \%$ & $60.59 \%$ & $61 \%$ \\
$f_{d j}$ & $4.37 \%$ & $0.93 \%$ & $0.42 \%$ \\
\hline
\end{tabular}

characteristics, which should not be neglected for a deeper investigation.

Finally, given the previously described test and the related muscle torque, shown in Figure 6, then the mean power associated with the opening and closing of the index finger at maximum velocity in the absence of load can be calculated: it is equal to $1.3 \mathrm{~W}$. The maximum power for the MCP joint in the absence of load is $1.24 \mathrm{~W}$, the maximum power for the PIP joint is $1.94 \mathrm{~W}$, and for the DIP joint it is $0.86 \mathrm{~W}$. This value constitutes a correction of the maximum power estimation for the finger joints, reported by Hasser [18], which states that the absence of external load corresponds to zero muscle torque.

\section{Conclusions}

An exhaustive study of the human hand was performed, dealing with the kinematics of the human hand and showing the 
TABLE 11: Anthropometric data and numerical constants used for simulation.

\begin{tabular}{lcc}
\hline$m_{1}=7.05 \mathrm{~g}$ & $m_{2}=3.97 \mathrm{~g}$ & $m_{3}=2.70 \mathrm{~g}$ \\
$I_{1}=1000 \mathrm{gmm}^{2}$ & $I_{2}=240 \mathrm{gmm}^{2}$ & $I_{3}=120 \mathrm{gmm}^{2}$ \\
$k_{1}=0.0902 \mathrm{Nm}$ & $k_{2}=0.0902 \mathrm{Nm}$ & $k_{3}=0.0902 \mathrm{Nm}$ \\
$c_{1}=0.0225 \mathrm{Nms}$ & $c_{2}=0.0225 \mathrm{Nms}$ & $c_{3}=0.0225 \mathrm{Nms}$ \\
$L_{1}=\left[\begin{array}{lll}50 & 0 & 0\end{array}\right]^{T} \mathrm{~mm}$ & $L_{2}=\left[\begin{array}{lll}20 & 0 & 0\end{array}\right]^{T} \mathrm{~mm}$ & $L_{3}=\left[\begin{array}{lll}25 & 0 & 0\end{array}\right]^{T} \mathrm{~mm}$ \\
$b_{1}=\left[\begin{array}{lll}25 & 0 & 0\end{array}\right]^{T} \mathrm{~mm}$ & $b_{2}=\left[\begin{array}{lll}10 & 0 & 0\end{array}\right]^{T} \mathrm{~mm}$ & $b_{3}=\left[\begin{array}{lll}12.5 & 0 & 0\end{array}\right]^{T} \mathrm{~mm}$ \\
$e_{1}=\left[\begin{array}{lll}25 & -8 & 0\end{array}\right]^{T} \mathrm{~mm}$ & $e_{2}=\left[\begin{array}{lll}10 & -7 & 0\end{array}\right]^{T} \mathrm{~mm}$ & $e_{3}=\left[\begin{array}{lll}12 & -6 & 0\end{array}\right]^{T} \mathrm{~mm}$ \\
\hline
\end{tabular}

matrices with the $\mathrm{MDH}$ parameters and detailed equations for both the direct and inverse kinematics of the hand. In addition, the dynamics of a single finger was analyzed and finally written using the same reference systems as per the kinematics. A case study was proposed, and a simulation was completed using the provided anthropometric data, in order to investigate the capabilities of the proposed analytical system.

The results of the current study can be exploited to conceive future hand devices. On one side, direct and inverse kinematics constitute preliminary stages for the development of any structure similar to the human hand, for instance, in robotic or rehabilitation hands projects. On the other side, dynamics equations allow the behavior of fingers to be simulated. Hence, the value of these equations is twofold: to model the finger itself, for the use in a control scheme model of a human-machine interface, such as a hand exoskeleton, or to model a finger-like architecture, such as a robotic hand.

\section{Appendices}

\section{A. Rototranslation Matrix Elements}

The $i$ subscript of the angles is omitted. First of all, the terms for the fingers ( $i=1$ to 4 ) are given. Consider

$$
\begin{aligned}
& Q_{i_{11}}=[\left(c \theta_{\mathrm{CMC}_{f / e}} c \theta_{\mathrm{MCP}_{a b / a d}}\right) c \theta_{\mathrm{MCP}_{f / e}} \\
&\left.-s \theta_{\mathrm{CMC}_{f / e}} s \theta_{\mathrm{MCP}_{f / e}}\right] \\
& \times\left(c \theta_{\mathrm{PIP}_{f / e}} c \theta_{\mathrm{DIP}_{f / e}}-s \theta_{\mathrm{PIP}_{f / e}} s \theta_{\mathrm{DIP}_{f / e}}\right) \\
&- {\left[\left(c \theta_{\mathrm{CMC}_{f / e}} c \theta_{\mathrm{MCP}_{a b / a d}}\right) s \theta_{\mathrm{MCP}_{f / e}}\right.} \\
&\left.+s \theta_{\mathrm{CMC}_{f / e}} c \theta_{\mathrm{MCP}_{f / e}}\right] \\
& \times\left(s \theta_{\mathrm{PIP}_{f / e}} c \theta_{\mathrm{DIP}_{f / e}}+c \theta_{\mathrm{PIP}_{f / e}} s \theta_{\mathrm{DIP}_{f / e}}\right), \\
& Q_{i_{12}}=\left[\left(c \theta_{\mathrm{CMC}_{f / e}} c \theta_{\mathrm{MCP}_{a b / a d}}\right) c \theta_{\mathrm{MCP}_{f / e}}\right. \\
&\left.-s \theta_{\mathrm{CMC}_{f / e}} s \theta_{\mathrm{MCP}_{f / e}}\right] \\
& \times\left(-c \theta_{\mathrm{PIP}_{f / e}} s \theta_{\mathrm{DIP}_{f / e}}-s \theta_{\mathrm{PIP}_{f / e}} c \theta_{\mathrm{DIP}_{f / e}}\right)
\end{aligned}
$$

$$
\begin{aligned}
& \text { - }\left[\left(c \theta_{\mathrm{CMC}_{f / e}} c \theta_{\mathrm{MCP}_{a b / a d}}\right) s \theta_{\mathrm{MCP}_{f / e}}\right. \\
& \left.+s \theta_{\mathrm{CMC}_{f / e}} c \theta_{\mathrm{MCP}_{f / e}}\right] \\
& \times\left(-s \theta_{\operatorname{PIP}_{f / e}} s \theta_{\mathrm{DIP}_{f / e}}+c \theta_{\mathrm{PIP}_{f / e}} c \theta_{\mathrm{DIP}_{f / e}}\right), \\
& Q_{i_{13}}=c \theta_{\mathrm{CMC}_{f / e}} s \theta_{\mathrm{MCP}_{a b / a d}} \text {, } \\
& Q_{i_{14}}=\left[\left(c \theta_{\mathrm{CMC}_{f / e}} c \theta_{\mathrm{MCP}_{a b / a d}}\right) c \theta_{\mathrm{MCP}_{f / e}}\right. \\
& \left.-s \theta_{\mathrm{CMC}_{f / e}} s \theta_{\mathrm{MCP}_{f / e}}\right] \\
& \times\left[L_{t i_{x}}\left(c \theta_{\mathrm{PIP}_{f / e}} c \theta_{\mathrm{DIP}_{f / e}}-s \theta_{\mathrm{PIP}_{f / e}} s \theta_{\mathrm{DIP}_{f / e}}\right)\right. \\
& +L_{t i_{y}}\left(-c \theta_{\mathrm{PIP}_{f / e}} s \theta_{\mathrm{DIP}_{f / e}}-s \theta_{\mathrm{PIP}_{f / e}} c \theta_{\mathrm{DIP}_{f / e}}\right) \\
& \left.+L_{1 i}+L_{2 i} c \theta_{\mathrm{PIP}_{f / e}}\right] \\
& -\left[\left(c \theta_{\mathrm{CMC}_{f / e}} c \theta_{\mathrm{MCP}_{a b / a d}}\right) s \theta_{\mathrm{MCP}_{f / e}}\right. \\
& \left.+s \theta_{\mathrm{CMC}_{f / e}} c \theta_{\mathrm{MCP}_{f / e}}\right] \\
& \times\left[L_{t i_{x}}\left(s \theta_{\mathrm{PIP}_{f / e}} c \theta_{\mathrm{DIP}_{f / e}}+c \theta_{\mathrm{PIP}_{f / e}} s \theta_{\mathrm{DIP}_{f / e}}\right)\right. \\
& +L_{t i i_{y}}\left(-s \theta_{\mathrm{PIP}_{f / e}} s \theta_{\mathrm{DIP}_{f / e}}+c \theta_{\mathrm{PIP}_{f / e}} c \theta_{\mathrm{DIP}_{f / e}}\right) \\
& \left.+L_{2 i} s \theta_{\mathrm{PIP}_{f / e}}\right] \\
& +\left(c \theta_{\mathrm{CMC}_{f / e}} s \theta_{\mathrm{MCP}_{a b / a d}}\right) L_{t i_{z}}+L_{0 i} c \theta_{\mathrm{CMC}_{f / e}}, \\
& Q_{i_{21}}=s \theta_{\mathrm{MCP}_{a b / a d}} c \theta_{\mathrm{MCP}_{f / e}} \\
& \times\left(c \theta_{\mathrm{PIP}_{f / e}} c \theta_{\mathrm{DIP}_{f / e}}-s \theta_{\mathrm{PIP}_{f / e}} s \theta_{\mathrm{DIP}_{f / e}}\right) \\
& -s \theta_{\mathrm{MCP}_{a b / a d}} s \theta_{\mathrm{MCP}_{f / e}} \\
& \times\left(s \theta_{\operatorname{PIP}_{f / e}} c \theta_{\mathrm{DIP}_{f / e}}+c \theta_{\mathrm{PIP}_{f / e}} s \theta_{\mathrm{DIP}_{f / e}}\right), \\
& Q_{i_{22}}=s \theta_{\mathrm{MCP}_{a b / a d}} c \theta_{\mathrm{MCP}_{f / e}} \\
& \times\left(-c \theta_{\operatorname{PIP}_{f / e}} s \theta_{\mathrm{DIP}_{f / e}}-s \theta_{\mathrm{PIP}_{f / e}} c \theta_{\mathrm{DIP}_{f / e}}\right)
\end{aligned}
$$




$$
\begin{aligned}
& -s \theta_{\mathrm{MCP}_{a b / a d}} s \theta_{\mathrm{MCP}_{f / e}} \\
& \times\left(-s \theta_{\mathrm{PIP}_{f / e}} s \theta_{\mathrm{DIP}_{f / e}}+c \theta_{\mathrm{PIP}_{f / e}} c \theta_{\mathrm{DIP}_{f / e}}\right), \\
& Q_{i_{23}}=-c \theta_{\mathrm{MCP}_{a b / a d}}, \\
& Q_{i_{24}}=s \theta_{\mathrm{MCP}_{a b / a d}} c \theta_{\mathrm{MCP}_{f / e}} \\
& \times\left[L_{t i_{x}}\left(c \theta_{\mathrm{PIP}_{f / e}} c \theta_{\mathrm{DIP}_{f / e}}-s \theta_{\mathrm{PIP}_{f / e}} s \theta_{\mathrm{DIP}_{f / e}}\right)\right. \\
& +L_{t i_{y}}\left(-c \theta_{\mathrm{PIP}_{f / e}} s \theta_{\mathrm{DIP}_{f / e}}-s \theta_{\mathrm{PIP}_{f / e}} c \theta_{\mathrm{DIP}_{f / e}}\right) \\
& \left.+L_{1 i}+L_{2 i} c \theta_{\mathrm{PIP}_{f / e}}\right]-s \theta_{\mathrm{MCP}_{a b / a d}} s \theta_{\mathrm{MCP}_{f / e}} \\
& \times\left[L_{t i_{x}}\left(s \theta_{\mathrm{PIP}_{f / e}} c \theta_{\mathrm{DIP}_{f / e}}+c \theta_{\mathrm{PIP}_{f / e}} s \theta_{\mathrm{DIP}_{f / e}}\right)\right. \\
& +L_{t i_{y}}\left(-s \theta_{\mathrm{PIP}_{f / e}} s \theta_{\mathrm{DIP}_{f / e}}+c \theta_{\mathrm{PIP}_{f / e}} c \theta_{\mathrm{DIP}_{f / e}}\right) \\
& \left.+L_{2 i} s \theta_{\mathrm{PIP}_{f / e}}\right]+\left(-c \theta_{\mathrm{MCP}_{a b / a d}}\right) L_{t i_{z}}, \\
& Q_{i_{31}}=\left\{\left(s \theta_{\mathrm{CMC}_{f / e}} c \theta_{\mathrm{MCP}_{a b / a d}}\right) c \theta_{\mathrm{MCP}_{f / e}}\right. \\
& \left.+c \theta_{\mathrm{CMC}_{f / e}} s \theta_{\mathrm{MCP}_{f / e}}\right\} \\
& \times\left(c \theta_{\mathrm{PIP}_{f / e}} c \theta_{\mathrm{DIP}_{f / e}}-s \theta_{\mathrm{PIP}_{f / e}} s \theta_{\mathrm{DIP}_{f / e}}\right) \\
& +\left\{-\left(s \theta_{\mathrm{CMC}_{f / e}} c \theta_{\mathrm{MCP}_{a b / a d}}\right) s \theta_{\mathrm{MCP}_{f / e}}\right. \\
& \left.+c \theta_{\mathrm{CMC}_{f / e}} c \theta_{\mathrm{MCP}_{f / e}}\right\} \\
& \times\left(s \theta_{\mathrm{PIP}_{f / e}} c \theta_{\mathrm{DIP}_{f / e}}+c \theta_{\mathrm{PIP}_{f / e}} s \theta_{\mathrm{DIP}_{f / e}}\right), \\
& Q_{i_{32}}=\left\{\left(s \theta_{\mathrm{CMC}_{f / e}} c \theta_{\mathrm{MCP}_{a b / a d}}\right) c \theta_{\mathrm{MCP}_{f / e}}\right. \\
& \left.+c \theta_{\mathrm{CMC}_{f / e}} s \theta_{\mathrm{MCP}_{f / e}}\right\} \\
& \times\left(-c \theta_{\mathrm{PIP}_{f / e}} s \theta_{\mathrm{DIP}_{f / e}}-s \theta_{\mathrm{PIP}_{f / e}} c \theta_{\mathrm{DIP}_{f / e}}\right) \\
& +\left\{-\left(s \theta_{\mathrm{CMC}_{f / e}} c \theta_{\mathrm{MCP}_{a b / a d}}\right) s \theta_{\mathrm{MCP}_{f / e}}\right. \\
& \left.+c \theta_{\mathrm{CMC}_{f / e}} c \theta_{\mathrm{MCP}_{f / e}}\right\} \\
& \times\left(-s \theta_{\mathrm{PIP}_{f / e}} s \theta_{\mathrm{DIP}_{f / e}}+c \theta_{\mathrm{PIP}_{f / e}} c \theta_{\mathrm{DIP}_{f / e}}\right), \\
& Q_{i_{33}}=s \theta_{\mathrm{CMC}_{f / e}} s \theta_{\mathrm{MCP}_{a b / a d}} \text {, } \\
& Q_{i_{34}}=\left\{\left(s \theta_{\mathrm{CMC}_{f / e}} c \theta_{\mathrm{MCP}_{a b / a d}}\right) c \theta_{\mathrm{MCP}_{f / e}}\right. \\
& \left.+c \theta_{C M C_{f / e}} s \theta_{M C P_{f / e}}\right\} \\
& \times\left[L_{t i_{x}}\left(c \theta_{\mathrm{PIP}_{f / e}} c \theta_{\mathrm{DIP}_{f / e}}-s \theta_{\mathrm{PIP}_{f / e}} s \theta_{\mathrm{DIP}_{f / e}}\right)\right. \\
& +L_{t i_{y}}\left(-c \theta_{\mathrm{PIP}_{f / e}} s \theta_{\mathrm{DIP}_{f / e}}-s \theta_{\mathrm{PIP}_{f / e}} c \theta_{\mathrm{DIP}_{f / e}}\right)
\end{aligned}
$$

$$
\begin{gathered}
\left.+L_{1 i}+L_{2 i} c \theta_{\mathrm{PIP}_{f / e}}\right] \\
+\left\{-\left(s \theta_{\mathrm{CMC}_{f / e} c} c \theta_{\mathrm{MCP}_{a b / a d}}\right) s \theta_{\mathrm{MCP}_{f / e}}\right. \\
\left.+c \theta_{\mathrm{CMC}_{f / e}} c \theta_{\left.\mathrm{MCP}_{f / e}\right\}}\right\} \\
\times\left[L_{t i_{x}}\left(s \theta_{\mathrm{PIP}_{f / e}} c \theta_{\mathrm{DIP}_{f / e}}+c \theta_{\mathrm{PIP}_{f / e}} s \theta_{\mathrm{DIP}_{f / e}}\right)\right. \\
+L_{t i_{y}}\left(-s \theta_{\mathrm{PIP}_{f / e}} s \theta_{\mathrm{DIP}_{f / e}}+c \theta_{\mathrm{PIP}_{f / e}} c \theta_{\mathrm{DIP}_{f / e}}\right) \\
\left.+L_{2 i} s \theta_{\mathrm{PIP}_{f / e}}\right] \\
+\left(s \theta_{\mathrm{CMC}_{f / e}} s \theta_{\mathrm{MCP}_{a b / a d}}\right) L_{t i_{z}}+L_{0 i} s \theta_{\mathrm{CMC}_{f / e}} .
\end{gathered}
$$

Now, the terms for the rototranslation matrix of the thumb $(i=0)$ are reported. Take

$$
\begin{aligned}
& Q_{0_{11}}=\left[c \theta_{\mathrm{TMC}_{a b / a d}} c \theta_{\mathrm{TMC}_{f / e}}\right] \\
& \times\left(c \theta_{\mathrm{MCP}_{f / e}} c \theta_{\mathrm{IP}_{f / e}}-s \theta_{\mathrm{MCP}_{f / e}} s \theta_{\mathrm{IP}_{f / e}}\right) \\
& +\left[-c \theta_{\mathrm{TMC}_{a b / a d}} s \theta_{\mathrm{TMC}_{f / e}}\right] \\
& \times\left(s \theta_{\mathrm{MCP}_{f / e}} c \theta_{\mathrm{IP}_{f / e}}+c \theta_{\mathrm{MCP}_{f / e}} s \theta_{\mathrm{IP}_{f / e}}\right), \\
& Q_{0_{12}}=\left[c \theta_{\mathrm{TMC}_{a b / a d}} c \theta_{\mathrm{TMC}_{f / e}}\right] \\
& \times\left(-c \theta_{\mathrm{MCP}_{f / e}} s \theta_{\mathrm{IP}_{f / e}}-s \theta_{\mathrm{MCP}_{f / e}} c \theta_{\mathrm{IP}_{f / e}}\right) \\
& +\left[-c \theta_{\mathrm{TMC}_{a b / a d}} s \theta_{\mathrm{TMC}_{f / e}}\right] \\
& \times\left(-s \theta_{\mathrm{MCP}_{f / e}} s \theta_{\mathrm{IP}_{f / e}}+c \theta_{\mathrm{MCP}_{f / e}} c \theta_{\mathrm{IP}_{f / e}}\right), \\
& Q_{0_{13}}=s \theta_{\mathrm{TMC}_{a b / a d}}, \\
& Q_{0_{14}}=\left[c \theta_{\mathrm{TMC}_{a b / a d}} c \theta_{\mathrm{TMC}_{f / e}}\right] \\
& \times\left[L_{t 0 \_x}\left(c \theta_{\mathrm{MCP}_{f / e}} c \theta_{\mathrm{IP}_{f / e}}-s \theta_{\mathrm{MCP}_{f / e}} s \theta_{\mathrm{IP}_{f / e}}\right)\right. \\
& +L_{t 0 \_y}\left(-c \theta_{\mathrm{MCP}_{f / e}} s \theta_{\mathrm{IP}_{f / e}}-s \theta_{\mathrm{MCP}_{f / e}} c \theta_{\mathrm{IP}_{f / e}}\right) \\
& \left.+L_{10} c \theta_{\mathrm{MCP}_{f / e}}+L_{00}\right] \\
& +\left[-c \theta_{\mathrm{TMC}_{a b / a d}} s \theta_{\mathrm{TMC}_{f / e}}\right]
\end{aligned}
$$

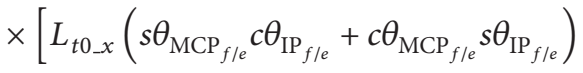

$$
\begin{aligned}
& +L_{t 0 \_y}\left(-s \theta_{\mathrm{MCP}_{f / e}} s \theta_{\mathrm{IP}_{f / e}}+c \theta_{\mathrm{MCP}_{f / e}} c \theta_{\mathrm{IP}_{f / e}}\right) \\
& \left.+L_{10} s \theta_{\mathrm{MCP}_{f / e}}\right]+L_{t 0 \_} s \theta_{\mathrm{TMC}_{a b / a d}},
\end{aligned}
$$




$$
\begin{aligned}
Q_{0_{21}}= & {\left[s \theta_{\mathrm{TMC}_{a b / a d}} c \theta_{\mathrm{TMC}_{f / e}}\right] } & \times\left[L_{t 0_{-} x}\left(s \theta_{\mathrm{MCP}_{f / e}} c \theta_{\mathrm{IP}_{f / e}}+c \theta_{\mathrm{MCP}_{f / e}} s \theta_{\mathrm{IP}_{f / e}}\right)\right. \\
& \times\left(c \theta_{\mathrm{MCP}_{f / e}} c \theta_{\mathrm{IP}_{f / e}}-s \theta_{\mathrm{MCP}_{f / e}} s \theta_{\mathrm{IP}_{f / e}}\right) & +L_{t 0-y}\left(-s \theta_{\mathrm{MCP}_{f / e}} s \theta_{\mathrm{IP}_{f / e}}+c \theta_{\mathrm{MCP}_{f / e}} c \theta_{\mathrm{IP}_{f / e}}\right) \\
& +\left[-s \theta_{\mathrm{TMC}_{a b / a d}} s \theta_{\mathrm{TMC}_{f / e}}\right] & \left.+L_{10} s \theta_{\mathrm{MCP}_{f / e}}\right] \\
& \times\left(s \theta_{\mathrm{MCP}_{f / e}} c \theta_{\mathrm{IP}_{f / e}}+c \theta_{\mathrm{MCP}_{f / e}} s \theta_{\mathrm{IP}_{f / e}}\right), &
\end{aligned}
$$$$
Q_{0_{22}}=\left[s \theta_{\mathrm{TMC}_{a b / a d}} c \theta_{\mathrm{TMC}_{f / e}}\right]
$$$$
\times\left(-c \theta_{\mathrm{MCP}_{f / e}} s \theta_{\mathrm{IP}_{f / e}}-s \theta_{\mathrm{MCP}_{f / e}} c \theta_{\mathrm{IP}_{f / e}}\right)
$$$$
+\left[-s \theta_{\mathrm{TMC}_{a b / a d}} s \theta_{\mathrm{TMC}_{f / e}}\right]
$$$$
\times\left(-s \theta_{\mathrm{MCP}_{f / e}} s \theta_{\mathrm{IP}_{f / e}}+c \theta_{\mathrm{MCP}_{f / e}} c \theta_{\mathrm{IP}_{f / e}}\right),
$$$$
Q_{0_{23}}=-c \theta_{\mathrm{TMC}_{a b / a d}} \text {, }
$$$$
Q_{0_{24}}=\left[s \theta_{\mathrm{TMC}_{a b / a d}} c \theta_{\mathrm{TMC}_{f / e}}\right]
$$$$
\times\left[L_{t 0 \_x}\left(c \theta_{\mathrm{MCP}_{f / e}} c \theta_{\mathrm{IP}_{f / e}}-s \theta_{\mathrm{MCP}_{f / e}} s \theta_{\mathrm{IP}_{f / e}}\right)\right.
$$$$
+L_{t 0_{-} y}\left(-c \theta_{\mathrm{MCP}_{f / e}} s \theta_{\mathrm{IP}_{f / e}}-s \theta_{\mathrm{MCP}_{f / e}} c \theta_{\mathrm{IP}_{f / e}}\right)
$$$$
\left.+L_{10} c \theta_{\mathrm{MCP}_{f / e}}+L_{00}\right]
$$$$
+\left[-s \theta_{\mathrm{TMC}_{a b l a d}} s \theta_{\mathrm{TMC}_{f / e}}\right]
$$

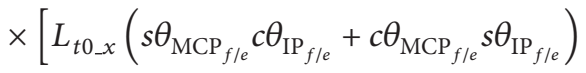$$
+L_{t 0-y}\left(-s \theta_{\mathrm{MCP}_{f / e}} s \theta_{\mathrm{IP}_{f / e}}+c \theta_{\mathrm{MCP}_{f / e}} c \theta_{\mathrm{IP}_{f / e}}\right)
$$$$
\left.+L_{10} s \theta_{\mathrm{MCP}_{f / e}}\right]-c \theta_{\mathrm{TMC}_{a b / a d}} L_{t 0-z},
$$$$
Q_{031}=s \theta_{\mathrm{TMC}_{f / e}}\left(c \theta_{\mathrm{MCP}_{f / e}} c \theta_{\mathrm{IP}_{f / e}}-s \theta_{\mathrm{MCP}_{f / e}} s \theta_{\mathrm{IP}_{f / e}}\right)
$$$$
+c \theta_{\mathrm{TMC}_{f / e}}\left(s \theta_{\mathrm{MCP}_{f / e}} c \theta_{\mathrm{IP}_{f / e}}+c \theta_{\mathrm{MCP}_{f / e}} s \theta_{\mathrm{IP}_{f / e}}\right),
$$$$
Q_{0_{32}}=s \theta_{\mathrm{TMC}_{f / e}}\left(-c \theta_{\mathrm{MCP}_{f / e}} s \theta_{\mathrm{IP}_{f / e}}-s \theta_{\mathrm{MCP}_{f / e}} c \theta_{\mathrm{IP}_{f / e}}\right)
$$

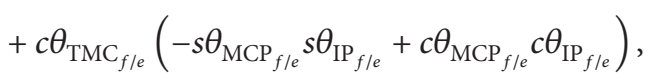$$
Q_{0_{33}}=0 \text {, }
$$$$
Q_{0_{34}}=s \theta_{\mathrm{TMC}_{f / e}}
$$$$
\times\left[L_{t 0 \_x}\left(c \theta_{\mathrm{MCP}_{f / e}} c \theta_{\mathrm{IP}_{f / e}}-s \theta_{\mathrm{MCP}_{f / e}} s \theta_{\mathrm{IP}_{f / e}}\right)\right.
$$$$
+L_{t 0-y}\left(-c \theta_{\mathrm{MCP}_{f / e}} s \theta_{\mathrm{IP}_{f / e}}-s \theta_{\mathrm{MCP}_{f / e}} c \theta_{\mathrm{IP}_{f / e}}\right)
$$$$
\left.+L_{10} c \theta_{\mathrm{MCP}_{f / e}}+L_{00}\right]+c \theta_{\mathrm{TMC}_{f / e}}
$$

\section{B. Dynamic Equation Terms}

Consider

$$
\begin{aligned}
& A_{1}=m_{1}\left[\left(-b_{1 x} s \theta_{1}-b_{1 y} c \theta_{1}\right)\left(-b_{1 x} \mathrm{~s} \theta_{1}-b_{1 y} \mathrm{c} \theta_{1}\right)\right. \\
& \left.+\left(b_{1 x} c \theta_{1}-b_{1 y} s \theta_{1}\right)\left(b_{1 x} c \theta_{1}-b_{1 y} \mathrm{~s} \theta_{1}\right)\right] \\
& +m_{2}\left[\left(-L_{1 x} s \theta_{1}-L_{1 y} c \theta_{1}\right)\left(-L_{1 x} s \theta_{1}-L_{1 y} c \theta_{1}\right)\right. \\
& \left.+\left(L_{1 x} c \theta_{1}-L_{1 y} s \theta_{1}\right)\left(L_{1 x} c \theta_{1}-L_{1 y} s \theta_{1}\right)\right] \\
& +m_{3}\left[\left(-L_{1 x} s \theta_{1}-L_{1 y} c \theta_{1}\right)\left(-L_{1 x} s \theta_{1}-L_{1 y} c \theta_{1}\right)\right. \\
& \left.+\left(L_{1 x} c \theta_{1}-L_{1 y} s \theta_{1}\right) \times\left(L_{1 x} c \theta_{1}-L_{1 y} s \theta_{1}\right)\right]+I_{1}, \\
& A_{2}=m_{2}\left[\left(-b_{2 x} s \theta_{12}-b_{2 y} c \theta_{12}\right)\left(-L_{1 x} s \theta_{1}-L_{1 y} c \theta_{1}\right)\right. \\
& \left.+\left(+b_{2 x} c \theta_{12}-b_{2 y} s \theta_{12}\right)\left(L_{1 x} c \theta_{1}-L_{1 y} s \theta_{1}\right)\right] \\
& +m_{3}\left[\left(-L_{2 x} s \theta_{12}-L_{2 y} c \theta_{12}\right)\left(-L_{1 x} s \theta_{1}-L_{1 y} c \theta_{1}\right)\right. \\
& \left.+\left(+L_{2 x} c \theta_{12}-L_{2 y} s \theta_{12}\right)\left(L_{1 x} c \theta_{1}-L_{1 y} s \theta_{1}\right)\right], \\
& A_{3}=m_{3}\left[\left(-b_{3 x} s \theta_{123}-b_{3 y} c \theta_{123}\right)\left(-L_{1 x} s \theta_{1}-L_{1 y} c \theta_{1}\right)\right. \\
& \left.+\left(+b_{3 x} c \theta_{123}-b_{3 y} s \theta_{123}\right)\left(L_{1 x} c \theta_{1}-L_{1 y} s \theta_{1}\right)\right], \\
& A_{4}=m_{1}\left[\left(-b_{1 x} \dot{\theta_{1}} s \theta_{1}-b_{1 y} \dot{\theta_{1}} c \theta_{1}\right)\left(-b_{1 x} \dot{\theta_{1}} c \theta_{1}+b_{1 y} \dot{\theta_{1}} s \theta_{1}\right)\right. \\
& \left.+\left(b_{1 x} c \theta_{1}-b_{1 y} s \theta_{1}\right)\left(-b_{1 x} s \theta_{1}-b_{1 y} c \theta_{1}\right) \dot{\theta_{1}}\right] \\
& +m_{2}\left[-\left(-L_{1 x} \dot{\theta}_{1}^{2} c \theta_{1}+L_{1 y} \dot{\theta}_{1}^{2} s \theta_{1}\right.\right. \\
& \left.-b_{2 x} \dot{\theta}_{12}^{2} c \theta_{12}+b_{2 y} \dot{\theta}_{12}^{2} s \theta_{12}\right) \\
& \times\left(-L_{1 x} s \theta_{1}-L_{1 y} c \theta_{1}\right) \\
& \text { - }\left(-L_{1 x} \dot{\theta}_{1}^{2} s \theta_{1}-L_{1 y} \dot{\theta}_{1}^{2} c \theta_{1}-b_{2 x} \dot{\theta}_{12}^{2} s \theta_{12}\right. \\
& \left.\left.-b_{2 y} \dot{\theta}_{12}^{2} c \theta_{12}\right)\left(L_{1 x} c \theta_{1}-L_{1 y} s \theta_{1}\right)\right] \\
& +m_{3}\left[-\left(-L_{1 x} \dot{\theta}_{1}^{2} c \theta_{1}+L_{1 y} \dot{\theta}_{1}^{2} s \theta_{1}-L_{2 x} \dot{\theta}_{12}^{2} c \theta_{12}\right.\right. \\
& \left.+L_{2 y} \dot{\theta}_{12}^{2} s \theta_{12}-b_{3 x} \dot{\theta}_{123}^{2} c \theta_{123}+b_{3 y} \dot{\theta}_{123}^{2} s \theta_{123}\right) \\
& \times\left(-L_{1 x} s \theta_{1}-L_{1 y} c \theta_{1}\right) \\
& -\left(-L_{1 x} \dot{\theta}_{1}^{2} s \theta_{1}-L_{1 y} \dot{\theta}_{1}^{2} c \theta_{1}-L_{2 x} \dot{\theta}_{12}^{2} s \theta_{12}\right.
\end{aligned}
$$




$$
\begin{aligned}
& \left.-L_{2 y} \dot{\theta}_{12}^{2} c \theta_{12}-b_{3 x} \dot{\theta}_{123}^{2} s \theta_{123}-b_{3 y} \dot{\theta}_{123}^{2} c \theta_{123}\right) \\
& \left.\times\left(L_{1 x} c \theta_{1}-L_{1 y} s \theta_{1}\right)\right] \\
& -\left(m_{1} g\left(b_{1 x} c \theta_{1}-b_{1 y} s \theta_{1}\right)+\left(m_{2}+m_{3}\right) g\right. \\
& \left.\times\left(L_{1 x} c \theta_{1}-L_{1 y} s \theta_{1}\right)+k_{1} \theta_{1}-k_{2}\left(\theta_{12}-\theta_{1}\right)\right) \\
& -c_{1} \dot{\theta}_{1}+c_{2}\left(\dot{\theta}_{12}-\dot{\theta}_{1}\right) \text {, } \\
& B_{1}=m_{2}\left[\left(-L_{1 x} s \theta_{1}-L_{1 y} c \theta_{1}\right)\left(-b_{2 x} s \theta_{12}-b_{2 y} c \theta_{12}\right)\right. \\
& \left.+\left(L_{1 x} c \theta_{1}-L_{1 y} s \theta_{1}\right)\left(b_{2 x} c \theta_{12}-b_{2 y} s \theta_{12}\right)\right] \\
& +m_{3}\left[\left(-L_{1 x} s \theta_{1}-L_{1 y} c \theta_{1}\right)\left(-L_{2 x} s \theta_{12}-L_{2 y} c \theta_{12}\right)\right. \\
& \left.+\left(L_{1 x} c \theta_{1}-L_{1 y} s \theta_{1}\right)\left(L_{2 x} c \theta_{12}-L_{2 y} s \theta_{12}\right)\right], \\
& B_{2}=m_{2}\left[\left(-b_{2 x} s \theta_{12}-b_{2 y} c \theta_{12}\right)\left(-b_{2 x} s \theta_{12}-b_{2 y} c \theta_{12}\right)\right. \\
& \left.+\left(+b_{2 x} c \theta_{12}-b_{2 y} s \theta_{12}\right)\left(b_{2 x} c \theta_{12}-b_{2 y} s \theta_{12}\right)\right] \\
& +m_{3}\left[\left(-L_{2 x} s \theta_{12}-L_{2 y} c \theta_{12}\right)\left(-L_{2 x} s \theta_{12}-L_{2 y} c \theta_{12}\right)\right. \\
& \left.+\left(+L_{2 x} c \theta_{12}\right)\left(L_{2 x} c \theta_{12}-L_{2 y} s \theta_{12}\right)\right]+I_{2}, \\
& B_{3}=m_{3}\left[\left(-b_{3 x} s \theta_{123}-b_{3 y} c \theta_{123}\right)\left(-L_{2 x} s \theta_{12}-L_{2 y} c \theta_{12}\right)\right. \\
& \left.+\left(+b_{3 x} c \theta_{123}-b_{3 y} s \theta_{123}\right)\left(L_{2 x} c \theta_{12}-L_{2 y} s \theta_{12}\right)\right], \\
& B_{4}=m_{2}\left[-\left(-L_{1 x} \dot{\theta}_{1}^{2} c \theta_{1}+L_{1 y} \dot{\theta}_{1}^{2} s \theta_{1}-b_{2 x} \dot{\theta}_{12}^{2} c \theta_{12}\right.\right. \\
& \left.+b_{2 y} \dot{\theta}_{12}^{2} s \theta_{12}\right)\left(-b_{2 x} s \theta_{12}-b_{2 y} c \theta_{12}\right) \\
& \text { - }\left(-L_{1 x} \dot{\theta}_{1}^{2} s \theta_{1}-L_{1 y} \dot{\theta}_{1}^{2} c \theta_{1}-b_{2 x} \dot{\theta}_{12}^{2} s \theta_{12}\right. \\
& \left.\left.-b_{2 y} \dot{\theta}_{12}^{2} c \theta_{12}\right)\left(b_{2 x} c \theta_{12}-b_{2 y} s \theta_{12}\right)\right] \\
& +m_{3}\left[-\left(-L_{1 x} \dot{\theta}_{1}^{2} c \theta_{1}+L_{1 y} \dot{\theta}_{1}^{2} s \theta_{1}-L_{2 x} \dot{\theta}_{12}^{2} c \theta_{12}\right.\right. \\
& +L_{2 y} \dot{\theta}_{12}^{2} s \theta_{12}-b_{3 x} \dot{\theta}_{123}^{2} c \theta_{123} \\
& \left.+b_{3 y} \dot{\theta}_{123}^{2} s \theta_{123}\right)\left(-L_{2 x} s \theta_{12}-L_{2 y} c \theta_{12}\right) \\
& \text { - }\left(-L_{1 x} \dot{\theta}_{1}^{2} s \theta_{1}-L_{1 y} \dot{\theta}_{1}^{2} c \theta_{1}-L_{2 x} \dot{\theta}_{12}^{2} s \theta_{12}\right. \\
& -L_{2 y} \dot{\theta}_{12}^{2} c \theta_{12}-b_{3 x} \dot{\theta}_{123}^{2} s \theta_{123} \\
& \left.\left.-b_{3 y} \dot{\theta}_{123}^{2} c \theta_{123}\right)\left(L_{2 x} c \theta_{12}-L_{2 y} s \theta_{12}\right)\right] \\
& -\left(m_{2} g\left(b_{2 x} c \theta_{12}-b_{2 y} s \theta_{12}\right)\right. \\
& +m_{3} g\left(L_{2 x} c \theta_{12}-L_{2 y} s \theta_{12}\right) \\
& \left.+k_{2}\left(\theta_{12}-\theta_{1}\right)-k_{3}\left(\theta_{123}-\theta_{12}\right)\right) \\
& -c_{2}\left(\dot{\theta}_{12}-\dot{\theta}_{1}\right)+c_{3}\left(\dot{\theta}_{123}-\dot{\theta}_{12}\right) \text {, }
\end{aligned}
$$

$$
\begin{aligned}
C_{1}=m_{3}[ & \left(-L_{1 x} s \theta_{1}-L_{1 y} c \theta_{1}\right)\left(-b_{3 x} s \theta_{123}-b_{3 y} c \theta_{123}\right) \\
+ & \left.\left(L_{1 x} c \theta_{1}-L_{1 y} s \theta_{1}\right)\left(b_{3 x} c \theta_{123}-b_{3 y} s \theta_{123}\right)\right] \\
C_{2}=m_{3}[ & \left(-L_{2 x} s \theta_{12}-L_{2 y} c \theta_{12}\right)\left(-b_{3 x} s \theta_{123}-b_{3 y} c \theta_{123}\right) \\
\times & \left.\left(+L_{2 x} c \theta_{12}-L_{2 y} s \theta_{12}\right)\left(b_{3 x} c \theta_{123}-b_{3 y} s \theta_{123}\right)\right] \\
C_{3}=m_{3}[ & \left(-b_{3 x} s \theta_{123}-b_{3 y} c \theta_{123}\right)\left(-b_{3 x} s \theta_{123}-b_{3 y} c \theta_{123}\right) \\
+ & \left(+b_{3 x} c \theta_{123}-b_{3 y} s \theta_{123}\right) \\
\times & \left.\left(b_{3 x} c \theta_{123}-b_{3 y} s \theta_{123}\right)\right]+I_{3}, \\
C_{4}=m_{3}[ & \left(-L_{1 x} \dot{\theta}_{1}^{2} c \theta_{1}+L_{1 y} \dot{\theta}_{1}^{2} s \theta_{1}-L_{2 x} \dot{\theta}_{12}^{2} c \theta_{12}\right. \\
& +L_{2 y} \dot{\theta}_{12}^{2} s \theta_{12}-b_{3 x} \dot{\theta}_{123}^{2} c \theta_{123} \\
& \left.+b_{3 y} \dot{\theta}_{123}^{2} s \theta_{123}\right)\left(-b_{3 x} s \theta_{123}-b_{3 y} c \theta_{123}\right) \\
& -\left(-L_{1 x} \dot{\theta}_{1}^{2} s \theta_{1}-L_{1 y} \dot{\theta}_{1}^{2} c \theta_{1}-L_{2 x} \dot{\theta}_{12}^{2} s \theta_{12}\right. \\
& \quad-L_{2 y} \ddot{\theta}_{12} s \theta_{12}-L_{2 y} \dot{\theta}_{12}^{2} c \theta_{12}+b_{3 x} \ddot{\theta}_{123} c \theta_{123} \\
& \left.\quad-b_{3 x} \dot{\theta}_{123}^{2} s \theta_{123}-b_{3 y} \dot{\theta}_{123}^{2} c \theta_{123}\right) \\
& \left.\times\left(b_{3 x} c \theta_{123}-b_{3 y} s \theta_{123}\right)\right] \\
-( & \left.m_{2} g\left(b_{2 x} c \theta_{12}-b_{2 y} s \theta_{12}\right)+m_{3} g\left(\theta_{12}\right)-k_{3}\left(\theta_{123}-\theta_{12}\right)\right)-c_{3}\left(\dot{\theta}_{123}-\dot{\theta}_{12}\right) .
\end{aligned}
$$

\section{References}

[1] "Eurobot Ground Prototype," http://www.esa.int/esaHS/ SEM9NCZGRMG_research_0.html.

[2] "What is a Robonaut?" http://robonaut.jsc.nasa.gov/default.asp.

[3] N. C. Jordan, J. H. Saleh, and D. J. Newman, "The extravehicular mobility unit: a review of environment, requirements, and design changes in the US spacesuit," Acta Astronautica, vol. 59, no. 12, pp. 1135-1145, 2006.

[4] C. N. Schabowsky, S. B. Godfrey, R. J. Holley, and P. S. Lum, "Development and pilot testing of HEXORR: Hand exoskeleton rehabilitation robot," Journal of NeuroEngineering and Rehabilitation, vol. 7, no. 1, article 36, 2010.

[5] http://www.nasa.gov/mission_pages/station/main/robo-glove .html.

[6] T. T. Worsnopp, M. A. Peshkin, J. E. Colgate, and D. G. Kamper, "An actuated finger exoskeleton for hand rehabilitation following stroke," in Proceedings of the 10th IEEE International Conference on Rehabilitation Robotics (ICORR '07), pp. 896-901, Noordwijk, The Netherlands, June 2007.

[7] N. S. K. Ho, K. Y. Tong, X. L. Hu et al., "An EMG-driven exoskeleton hand robotic training device on chronic stroke subjects: task training system for stroke rehabilitation," in Proceedings of the IEEE International Conference on Rehabilitation Robotics (Rehab Week Zurich), ETH Zurich Science City, Switzerland, July 2011. 
[8] P. Cerveri, N. Lopomo, A. Pedotti, and G. Ferrigno, "Derivation of centers and axes of rotation for wrist and fingers in a hand kinematic model: methods and reliability results," Annals of Biomedical Engineering, vol. 33, no. 3, pp. 402-412, 2005.

[9] J. W. Garrett, "Anthropometry of the hands of male air force flight personnel," Tech. Rep., Aerospace Medical Research Laboratory, Air Force Systems Command, Wright-Patterson Air Force Base, Ohio, USA, 1970.

[10] J. W. Garrett, "Anthropometry of the hands of female air force flight personnel," Tech. Rep., Aerospace Medical Research Laboratory, Air Force Systems Command, Wright-Patterson Air Force Base, Ohio, USA, 1970.

[11] S. R. Habib and N. N. Kamal, "Stature estimation from hand and phalanges lengths of Egyptians," Journal of Forensic and Legal Medicine, vol. 17, no. 3, pp. 156-160, 2010.

[12] O. P. Jasuja and G. Singh, "Estimation of stature from hand and phalange length," Journal of Indian Academy of Forensic Medicine, vol. 26, no. 3, pp. 100-106, 2004.

[13] S. Cobos, M. Ferre, M. A. Sanchéz-Urán, J. Ortego, and C. Peña, "Efficient human hand kinematics for manipulation tasks," in Proceedings of the IEEE/RSJ International Conference on Intelligent Robots and Systems (IROS '08), pp. 2246-2251, Acropolis Convention Center, Nice, France, September 2008.

[14] S. Cobos, M. Ferre, M. Sanchez, and J. Ortego, "Constraints for realistic hand manipulation," in Proceedings of the 10th Annual International Workshop on Presence (PRESENCE '07), pp. 369370, Barcelona, Spain, October 2007.

[15] H. Rijpkema and M. Girard, "Computer animation of knowledge-based human grasping," in Proceedings of the 18th Annual Conference on Computer Graphics and Interactive Techniques (SIGGRAPH '91), pp. 339-348, 1991.

[16] J. J. Craig, Introduction to Robotics, Mechanics and Control, Pearson Education International, 3rd edition, 1986.

[17] T. E. Milner and D. W. Franklin, "Characterization of multijoint finger stiffness: dependence on finger posture and force direction," IEEE Transactions on Biomedical Engineering, vol. 45, no. 11, pp. 1363-1375, 1998.

[18] C. J. Hasser, Force-Reflecting Anthropomorphic Hand Masters, Armstrong Lab, Crew Systems Directorate, Wright-Patterson Air Force Base, Ohio, USA, 1995.

[19] A. D. Deshpande, N. Gialias, and Y. Matsuoka, "Contributions of intrinsic visco-elastic torques during planar index finger and wrist movements," IEEE Transactions on Biomedical Engineering, vol. 59, no. 2, pp. 586-594, 2012.

[20] A. Z. Hajian and R. D. Howe, "Identification of the mechanical impedance at the human finger tip," Journal of Biomechanical Engineering, vol. 119, no. 1, pp. 109-114, 1997. 

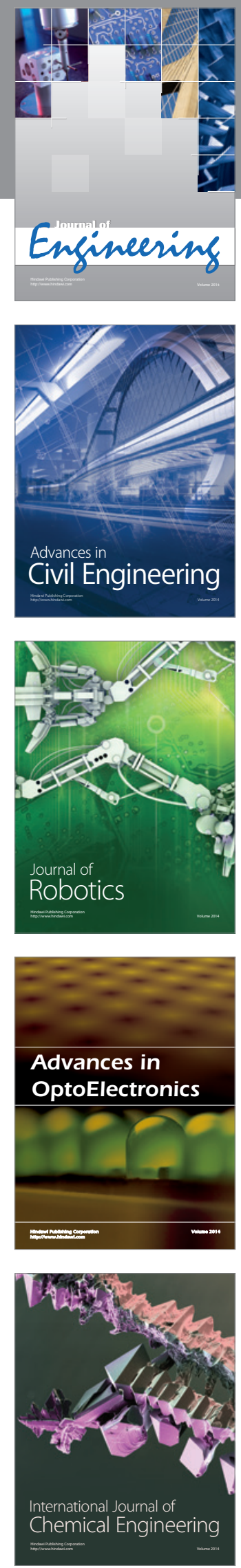

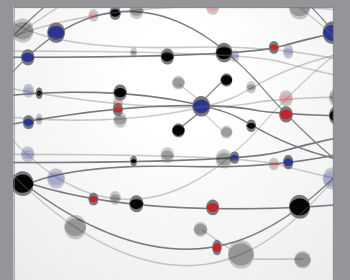

The Scientific World Journal
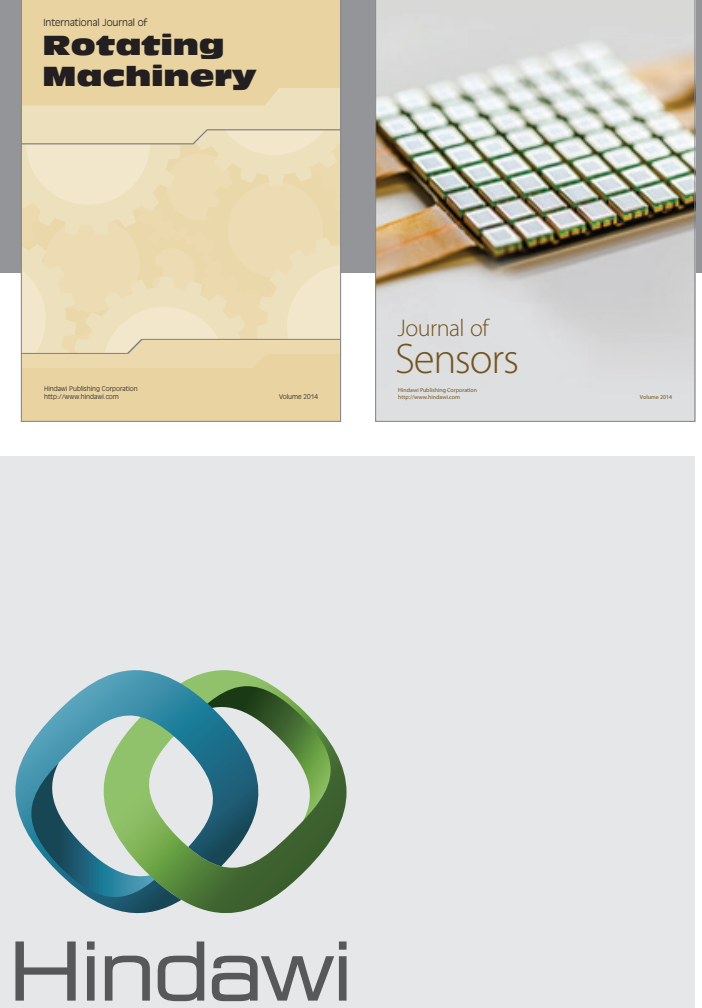

Submit your manuscripts at http://www.hindawi.com
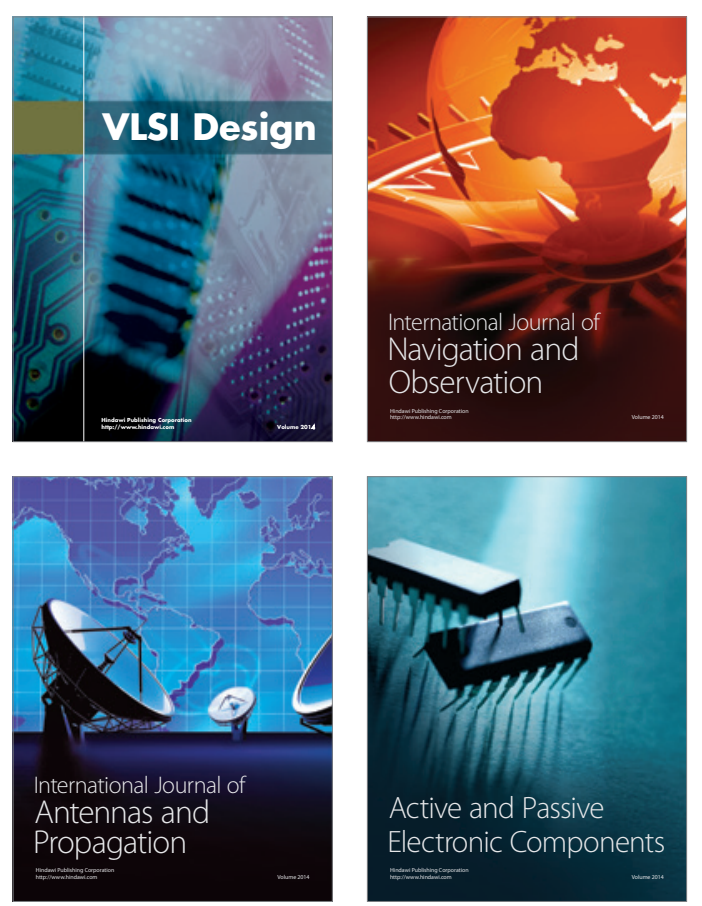
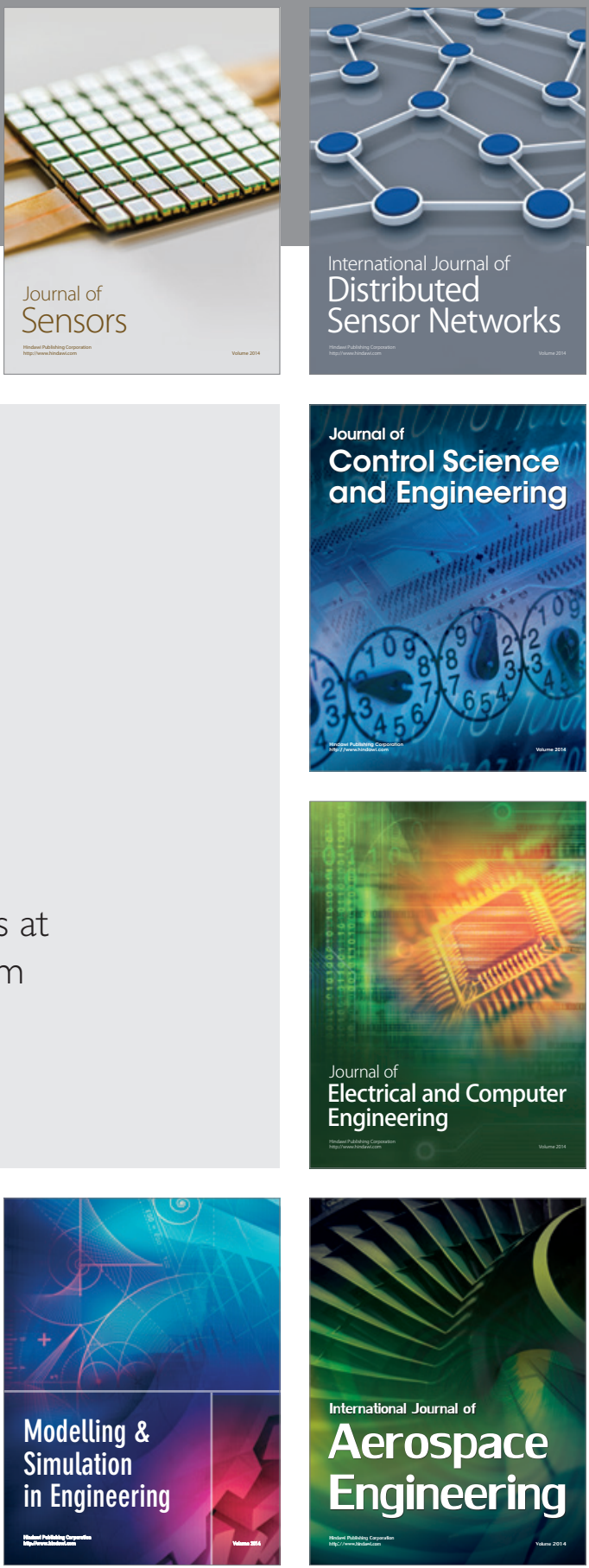

Journal of

Control Science

and Engineering
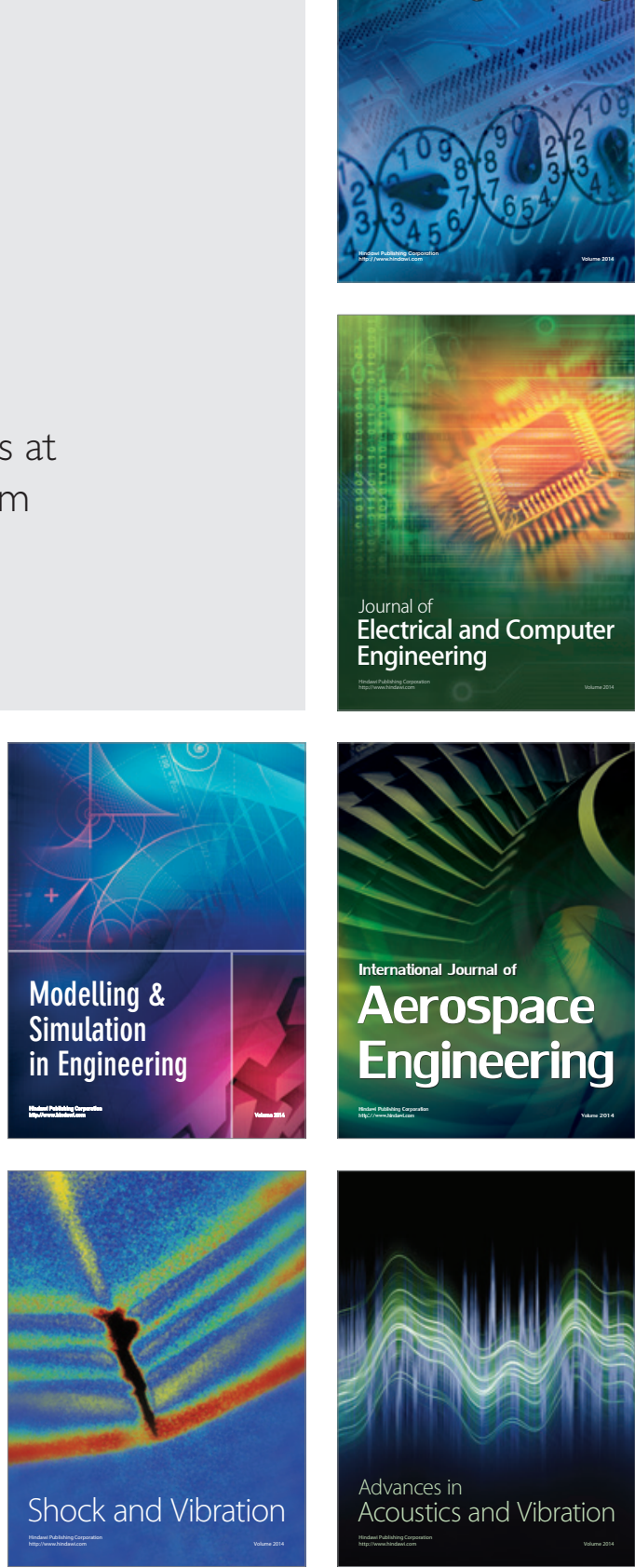